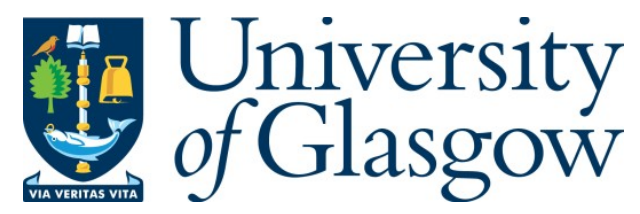

Barbopoulos, L. G., Paudyal, K. and Sudarsanam, S. (2018) Earnout deals: method of initial payment and acquirers' gains. European Financial Management, 24(59), pp. 792-828. (doi:10.1111/eufm.12135).

There may be differences between this version and the published version. You are advised to consult the publisher's version if you wish to cite from it.

This is the peer reviewed version of the following article:

Barbopoulos, L. G., Paudyal, K. and Sudarsanam, S. (2018) Earnout deals: method of initial payment and acquirers' gains. European Financial Management, 24(59), pp. 792-828, which has been published in final form at 10.1111/eufm.12135. This article may be used for non-commercial purposes in accordance with Wiley Terms and Conditions for Self-Archiving.

http://eprints.gla.ac.uk/145346/

Deposited on: 01 September 2017

Enlighten - Research publications by members of the University of Glasgow http://eprints.gla.ac.uk 


\section{Earnout deals: Method of initial payment and acquirers' gains*}

\section{Leonidas G. Barbopoulos}

Adam Smith Business School,

University of Glasgow, University Avenue, Glasgow, G12 8QQ, UK

Email: leonidas.barbopoulos@glasgow.ac.uk

Tel: +44 (0) 1413307229

\section{Krishna Paudyal}

Strathclyde Business School

University of Strathclyde, Glasgow, G4 0QU, UK

Email: krishna.paudyal@strath.ac.uk

Tel: +44(0)1415482894

\section{Sudi Sudarsanam}

Cranfield School of Management,

Cranfield, MK43 0AL, UK

Email: p.s.sudarsanam@cranfield.ac.uk

${ }^{*}$ We acknowledge the comments and suggestions of John A. Doukas (the Editor), two anonymous referees, Jana Fidrmuc, Jens Hagendorff, and the participants of the Southwestern Finance Association conference (Albuquerque, 2013 where an earlier version of the paper was awarded 'Best paper in Corporate Finance'), EFMA Conference (Basel, Switzerland) 2016, BAFA (Scottish) conference 2016, and the participants of the seminar series of the University of St. Andrews, University of Glasgow, Old Dominion University, Luxemburg School of Finance, King's College London, College of William and Mary, University of Vienna, Vienna Graduate School of Finance, and University of St. Gallen in earlier versions of the paper. Any remaining errors are ours. Please address all correspondence to Leonidas Barbopoulos (leonidas.barbopoulos@st-andrews.ac.uk). 


\title{
Earnout deals: Method of initial payment and acquirers' gains
}

\begin{abstract}
We analyze the implications of initial payment methods in earnout deals on acquirers' gains. The results, which are robust to self-selection bias and alternative model specifications, reveal that earnout deals outperform non-earnout deals. The acquirers gain the most from earnout deals when both initial and deferred payments are in stocks. The positive wealth effect of the choice of initial payment method in earnout deals is more prominent in cross-border deals than in domestic deals. Overall, the earnout deals generate higher gains when both the initial and deferred payments help spread the risk between the shareholders of acquiring and target firms.
\end{abstract}

Keywords: Earnout contracts; Initial payment in earnout deals; Asymmetric information; Acquirers' gains.

GEL classification: G34. 


\section{Earnout deals: Method of initial payment and acquirers' gains}

\section{Introduction}

In a seminal study of the effect of earnout deals on acquirers' gains Kohers and Ang (2000) show that such deals yield higher excess returns to acquirers than single up-front financed deals. ${ }^{1}$ In an earnout deal, the payment to target owners is made in two stages. The first stage payment (an initial payment at the time of the deal) can be in cash, stock, or a combination of these and other securities. ${ }^{2}$ The deferred (second part) payment is made over the earnout period and is conditional on the target reaching agreed milestones. The deferred payment could also be in cash, stock or a combination of cash and different securities. ${ }^{3}$ Earnout contracts have become popular in recent years, reaching $11 \%$ of total deals in 2009 from less than $2 \%$ in 1986. In spite of such growing popularity of earnout contracts in which a large proportion of the deal value (about two-thirds) is paid at the time of the deal, the effect of both the choice of methods of initial and second part payments on acquirers' abnormal returns remains to be investigated. This paper aims to fill this void. The findings of this analysis should be of interest to the managers and shareholders of firms that are

\footnotetext{
${ }^{1}$ Studies by Cain et al. (2011) for the US and Barbopoulos and Sudarsanam (2012) for the UK also show that among the domestic deals earnout deals yield higher returns to acquirers than single up-front payment deals.

${ }^{2}$ The average earnout component is about $33 \%$ of the total purchase consideration (Cain et al., 2011; Barbopoulos and Sudarsanam, 2012).

${ }^{3}$ Faccio and Masulis (2005, footnote 13) show that the balance is usually paid in cash. However, later in this paper, we show that in $55 \%$ of earnout deals (for which the breakdown is available) the second part payment is made in cash while stocks are used in $14 \%$ of the deals and the remaining deals (31\%) are settled in a mixture of cash \& stock. Hence, analysis of second payment also deserves attention.
} 
willing to engage in mergers and acquisitions (M\&As) and minimize the adverse effects of information asymmetry through risk sharing.

The choice of payment method in M\&A deals is often guided by the aim of mitigating the valuation risk which originates from information asymmetry between the merging firms for two reasons. First, one or both merging firms may hold private knowledge on their valuation which is not ex ante transparent to the other - a case of adverse selection or hidden knowledge. Second, one or both merging firms can take an action ex post that may harm the other - a case of moral hazard ${ }^{4}$ or hidden action. Studies show that adverse selection risk can be reduced by the judicious choice of the method of payment (Hansen, 1987; Eckbo et al., 1990). Neither cash nor stock payment that is delivered in a single up-front payment can factor the post-acquisition performance of the target in the deal value while an earnout contract does. The contingent form of consideration (earnout) seeks to achieve both the reduction of the adverse selection problem (i.e. ex ante overvaluation of the target firm due to target owners/managers hiding 'bad' information regarding the 'intrinsic' value of the firm) and the ex post moral hazard problem (i.e. contract failure due to shirking or the inability of a party to enforce contract compliance and performance delivery), thus contributing to the reduction in valuation risk for the acquiring firm. ${ }^{5}$

\footnotetext{
${ }^{4}$ Moral hazard arises when contractual performance cannot be precisely monitored or enforced due to weak contract formulation, imprecise performance measurement, or weak contract enforcement remedies. For a discussion of the adverse selection and moral hazard perspectives on earnout contracts see Cain et al.
} (2011).

${ }^{5}$ Several other contractual mechanisms are available for enhancing M\&A deal success, such as: (a) termination fees, lockups, and material adverse change clauses that are designed to prevent, or raise the cost of, either the acquirer or the target reneging on the deal, (b) collars that are designed to minimize the impact of short term adverse stock price movements and, (c) toeholds that are designed to increase the probability of deal success by the acquirer through buying up chunks of target shares. Unlike earnout contracts that are 
The attractiveness of earnout as a payment mechanism for mitigating the adverse selection and moral hazard problems has contributed to its increasing use in recent years (see Figure 1). The choice of initial payment method is also a matter of high strategic importance in managing the valuation risk. For instance, a combination of stock (as initial payment) and earnout may add more value to the acquirer as it provides a better risk sharing mechanism between the shareholders of the target and acquiring firms. Further, the choice of the method of payment in the second tranche (i.e. deferred payment) of the purchase consideration is also of strategic importance. For example, paying in stocks in both tranches (initial and second) is likely to send a stronger signal of acquirer management's strategy in sharing risk and the confidence of the target management to succeed, as agreement to an earnout or to stock as second stage payment attests to the latter's commitment or bonding. ${ }^{6}$ On the other hand, acquirers who are confident about the value of the merger may prefer to pay the up-front tranche in cash, so that they could limit the transfer of wealth gained from M\&As to target owners. Thus, in assessing the impact of earnout as a risk management tool, the interactive effect of the initial payment method and the second tranche earnout is critical and neither should be evaluated in isolation. Similarly, the analysis should provide due consideration to the method of payment used in the second tranche. The strategic decision of designing earnout with a particular combination of initial and second payments is expected to influence the gains to acquirers. For example, a stock-stock combination of first and second tranches may result in greater risk sharing than a

designed to manage valuation risk, these mechanisms are designed to eliminate transactional risk and not mitigate valuation risk. Hence, our primary objective in this paper is to analyze the impact of the combinations of payment methods in earnout deals in mitigating valuation risk in the context of domestic and foreign acquisitions.

${ }^{6}$ Restricted stock options could also be an effective method of bonding target managers to the long-run interests of the merged firms' shareholders. However, analysis of the effectiveness of such options, relative to that of earnout contracts, remains a matter for future empirical investigation. 
cash-stock combination and even more than a cash-cash combination. The implications of such a decision on acquirers' gains, however, remain to be investigated. We fill this void by analyzing the impact of the choice of initial and second payments in earnout deals on acquirers' gains.

\section{(Insert Figure 1 about here)}

Due to higher information asymmetry, adverse selection and moral hazard problems may be more aggravated in cross-border mergers and acquisitions (hereafter CBA) than in domestic deals. One possible way to minimize the implications of such risks is to enter into a contract that makes the target management more responsible for the performance of the target firm and hence makes the final pay-off contingent upon the post-acquisition performance of the target. Although the earnout contract offers such a possibility, there is no study that examines the comparative effects of the initial-and-deferred payment methods in earnout contracts on the gains of acquirers of domestic and foreign targets. This paper fills this void too.

The paper makes two distinct contributions to the literature. It is the first study to investigate the wealth effect of the initial and second part payment methods in earnout deals. It is also the first study to analyze the relative merits of combinations of payment methods in earnout contracts against other payment method combinations in both domestic and foreign acquisitions. The results show that significantly higher gains can be generated in earnout deals when the initial payment is made in stocks, or in a combination of cash \& stocks than when it is all-cash. Such a combination, where risk sharing is maximized, is more value enhancing in CBA than in domestic deals, indicating that an earnout contract with a superior risk sharing mechanism is more effective in CBA than in domestic deals. Moreover, as expected a double contingent payment mechanism embedded in earnout contracts that use stocks in both initial and second part payment generate even higher abnormal returns to acquirers. To ensure that the findings based on conventional methods are robust to potential self-selection biases with regard to endogeneity, we apply Propensity Score Matching (PSM) and Rosenbaum-bounds sensitivity methods.

The rest of the paper is organized thus. Section 2 discusses the relevance of deferred payment in managing the adverse selection and moral hazard problems in M\&As and develops testable propositions. 
In section 3 the sample selection process, the salient features of the sample, and the methods of analysis are described. The results are discussed in section 4 and section 5 concludes the paper.

\section{Deferred financing, adverse selection and moral hazard}

Both acquirers and targets face adverse selection risk in negotiating the value of a takeover deal. One way of mitigating this risk is to use the earnout in which the purchase consideration is divided into two parts an initial payment at the time of the deal, and another tranche of payment which is contingent upon the target's post-merger performance and ability to meet the predetermined goals under their own management. ${ }^{7}$ Earnout is often used to acquire targets whose value generally depends on the intangible assets of human creativity, efforts, and the flair of one or only a few individuals. Such firms often operate in the service or technology sectors and are privately owned. Valuing such companies, however, is immensely difficult and retaining the target management after acquisition may be a key consideration for acquirers. Earnout agreements provide a solution in such conditions. Cain et al. (2011) argue that earnout provides a solution when price negotiation between buyer and seller stalls. It incentivizes the target owners/managers by offering a direct link between agreed post-merger performance and the deal value. For

\footnotetext{
${ }^{7}$ Cain et al. (2011, p. 155) note that 'the contingent payment is almost always based on the post-acquisition performance of the target. In $90 \%$ of the cases (un-tabulated), the earnout is contingent on the performance of the target firm only, while in another $9 \%$ of the cases, it is contingent on the combined performance of the target and acquiring firms'. They also find that stock price is used as a performance measure in only $1.2 \%$ of cases (most targets in their sample are private firms). Accounting measures of profitability (e.g. cash flow, pre-tax income, gross profit, net income, earnings per share) are used in 52\% of cases while in $32 \%$ of cases a measure of sales is used; and non-financial measures (such as product development, securing specific contracts) are used in $12.2 \%$ of cases.
} 
the acquirer, it presents a solution to the moral hazard problem that the true potential of the target may not be achieved because of shirking or dereliction by target manager-owner(s).

Cash only deals are not effective in managing the risk of adverse selection and moral hazard since they lack the contingency element directly related to the post-acquisition performance of the target. An allstocks deal could be superior to a cash only deal as the target shareholders retain their interest in the combined firm and the risk is shared among the post-merger shareholders. An earnout contract, on the other hand, provides a more finely calibrated incentive mechanism as payment of the earnout component of the deal value is directly related to well-defined operating performance goals of the target. Similarly, the target owner-manager also gains from earnout as it allows ex post settlement that mitigates the effect of information asymmetry. Thus, earnout deals mitigate the information asymmetry effects on both acquirer and target shareholders. ${ }^{8}$

Since earnout provides a solution to adverse selection and moral hazard problems, it is likely to be of strategic relevance to acquirers in both CBA and domestic deals, compared to single up-front methods of payment (e.g. cash only, stocks only, or their combination). In earnout deals one of the most important strategic decisions that merging partners need to make is the choice of initial payment method. As a large proportion (about two thirds) of deal value is settled up front, paying initially in cash is likely to expose the acquiring firm to higher adverse selection risks while an exchange of stocks allows for higher risk sharing among the shareholders' merging firms. As noted earlier, the primary objective of an earnout contract is to

\footnotetext{
${ }^{8}$ It may be argued that instead of having an earnout contract the purchase consideration can be discounted to reflect the uncertainties associated with the value of the deal. Whilst the discounted deal value could be acceptable for the acquirer it may not be acceptable to the target owners as they may have better insight about the value of the target. Such a scenario may lead to a breakdown in negotiations. Earnout can alleviate the difficulty created by information asymmetry between the two merging partners and make a deal feasible as the ultimate value of the purchase consideration depends on the actual value added to the acquirer.
} 
minimize the post-merger valuation risk to both parties. Since initial payment in stocks supplements the role of earnout, a combination of stocks and earnout is likely to mitigate the adverse selection and moral hazard risks more effectively, especially for acquirers. This leads to our first hypothesis: 'Acquirers that settle their purchase consideration with a combination of stocks at the first stage and earnout gain more than the acquirers that combine cash at the first stage with earnout'.

An earnout contract in which both initial and second part payments are made in stocks offers higher protection to acquirers. Such a deal incentivizes the target management to ensure sound performance of the target during the earnout period as well as that of the merged firm after the second tranche has been paid. Therefore, the implications of the stock initial payment in earnout deals are likely to be more effective if the second part payment is also in stocks. On the other hand, if the second part payment is in cash, the target management may have incentives to maximize short-term gains (i.e. meeting the earnout targets) at the cost of long-term performance of the firm. Consequently, when the second part payment also leads to risk sharing, the acquirers' are expected to earn even higher excess returns from earnout deals.

Reuer et al. (2004) suggest that the likelihood of the use of earnout increases with uncertainty facing the acquiring firm. Adverse selection and moral hazard problems may be aggravated in CBA due to the unfamiliarity of the acquirer with the target firm's market environment, legal and regulatory impediments, lack of comparable accounting information about the target firm, differences in national and organizational cultures, lack of (or unfamiliarity with) infrastructure to carry out extensive due diligence, etc. While retaining local owner-managers in the target firm may perhaps be more critical for the success of a foreign acquisition than in the case of a domestic acquisition, difficulties in monitoring their performance and ensuring that they deliver performance consistent with the value objectives of the acquirer may give rise to moral hazard.

The discussion in the previous paragraph shows that the rationale for the use of earnout may be more compelling in CBA than in domestic deals; however, there is no study that examines the comparative effects of the initial payment method in earnout contracts on the gains of acquirers of domestic and foreign 
targets. Since the use of earnout can mitigate the more serious adverse selection and moral hazard risks associated with CBA, the impact of earnout on acquirers' gains may differ significantly between domestic and foreign deals, especially when the payment mechanism maximizes risk sharing opportunities. This leads to our second hypothesis: 'When the initial payment is made in stocks in earnout deals, acquirers gain more from the acquisitions of foreign targets than from the acquisitions of domestic targets.'

We examine both hypotheses under univariate and multivariate frameworks using the sample and methodology described in the next section.

\section{The Sample and Methodology}

\subsection{The sample}

The sample is comprised of takeover deals announced by US firms between 01/01/1986 and 31/12/2013; SDC Platinum records 283,220 such deals during the sample period. For a deal to remain in the sample, it must meet the following criteria. First, the acquirer is a US company listed on one of the major US Stock Exchanges (Nasdaq, New York, American, NYSE, Alternext, Pacific, and Boston) and has a market value of at least $\$ 1 \mathrm{~m}$, measured four weeks prior to the announcement of the bid. Second, to avoid the effects of very small deals, the deal value (excluding fees and expenses) needs to be at least $\$ 1 \mathrm{~m}$. Third, to ensure that the acquirer enjoys control of the target, only acquisitions of at least $50 \%$ of target equity are included. Fourth, targets of varying listing status (listed, private and subsidiary) and domicile (US or nonUS) are retained. Fifth, to avoid the confounding effects of multiple bids, bids announced within 5-days before or after another bid by the same acquirer are excluded. Deals involving Financial, Government agencies, and Utility firms as either the acquirer or the target are excluded from the sample. Finally, the daily stock price, market value, and market-to-book value of the acquirer need to be available from Datastream. 30,553 deals satisfy the criteria and remain in the sample.

Table 1 shows that the earnout activity spikes with the overall M\&A activity. On average about $6.0 \%$ of US deals (5.6\% of domestic and $10.4 \%$ of CBA) involve earnout contracts and the rest, i.e. $94.0 \%$, 
involve single up-front payments. ${ }^{9}$ The use of earnout has become more popular in recent years reaching $11 \%$ of total deals in 2009 from less than $1.9 \%$ in 1986.

Table 2 (Panel A) shows that the single largest group of M\&A deals involves public targets (51\%), followed by private (32\%) and subsidiary targets $(17 \%)$. The earnout financed deals involve approximately $75 \%$ private and $23 \%$ subsidiary target firms. ${ }^{10}$ The statistics show that larger deals are settled in cash \& stocks combined $(\$ 559 \mathrm{~m})$, followed by stocks only $(\$ 406 \mathrm{~m})$ and cash only payments $(\$ 282 \mathrm{~m})$. Among the earnout deals, deals with an initial cash payment are the largest $(\$ 120 \mathrm{~m})$ followed by a combination of multiple securities other than cash \& stocks (hereafter 'other') $(\$ 99 \mathrm{~m})$, by stocks $(\$ 80 \mathrm{~m})$ and by cash \& stocks $(\$ 75 \mathrm{~m})$. Acquirers using earnout are, on average, smaller across all portfolios classified by the methods of payment. Panel A further shows that among the earnout deals cash appears to be the most common form of initial payment (46\%), followed by other (23\%), cash \& stocks (19\%) and stocks (12\%). Among the non-earnout deals, cash only remains the dominant method of payment (65\%) followed by cash $\&$ stocks (18\%), and stocks only (16\%).

(Insert Tables 1 and 2 about here)

Panel B shows that acquirers using earnout have lower growth opportunities (with a market-tobook value ratio of 1.9) than non-earnout acquirers (3.4). The acquirers of foreign targets are more mature than the acquirers of domestic targets (14.3 years vs. 12.7 years) and acquirers using earnout are younger than those using non-earnout (11.4 years vs. 13.0 years). Among the earnout deals, acquirers are more mature (14.1 years) in deals that have cash initial payment while the younger ones ( 8.0 years) prefer stocks

\footnotetext{
${ }^{9}$ Our sample compares favorably with those of previous studies. For example, Cain et al. (2011) report that $3.9 \%$ of their sample includes earnout bids. Datar et al. (2001) report that $4.1 \%$ of their total sample involves earnout bids while Kohers and Ang (2000) report that 5.6\% of their sample uses earnout.

${ }^{10}$ Kohers and Ang (2000) report that almost 66\% (27\%) of earnout deals in the US involve privately held (divested subsidiary) targets.
} 
at the initial payment stage. Similar patterns in acquirer age are observed in single-up-front payment deals - mature acquirers (15.0 years) pay in cash while the younger acquirers ( 7.9 years) pay in stocks. The average value of earnout consideration is $\$ 29 \mathrm{~m}$. Finally, consistent with earlier evidence (Cain et al., 2011) the average earnout to total deal value ratio (relative earnout size) is about a third (34\%). For earnout deals in which the first payment is in stocks, the relative earnout size is $40 \%$ while it is only $32 \%$ (30\%) in deals that have a cash (cash \& stocks) initial payment. Such double contingent payments (stocks and earnout combined) are perhaps used in high risk deals to manage the valuation risk more effectively.

In addition, to test for the implications of second part payment on acquirers' gains, we hand collected data on the form of the deferred payment for a large number of sample deals. The relevant data were collected from the SEC EDGAR corporate filings (8-K and 10-K EDGAR corporate filings from 2003 until the end of 2013). We managed to obtain the details of second part payment for 723 out of 850 deals.

\subsection{Measurement of abnormal returns}

As in recent studies with similar sample features ${ }^{11}$ (e.g. Fuller et al., 2002), the announcement period abnormal returns are estimated using the market-adjusted model (equation 1):

$$
A R_{i t}=R_{i t}-R_{m t}
$$

where $A R_{i t}$ is the abnormal return of acquirer $i$ on day $t ; R_{i t}$ is the return of acquirer $i$ on day $t, R_{m t}$ is the value-weighted market return on day $t$. The announcement period cumulative excess return is the sum of

\footnotetext{
${ }^{11}$ The sample includes multiple target acquirers, making it impractical to have an estimation period that is free from the event under scrutiny. This makes the use of time series based asset pricing models inappropriate. Moreover, Brown and Warner (1980) show that the adjustment for the firm's systematic risk (beta) does not improve the precision of the short-term abnormal returns. Hence, the use of the market adjusted return should not affect the reliability of our findings.
} 
the abnormal returns over the 5-days ( $t-2$ to $t+2)$ surrounding the day of announcement of the acquisition, day 0 (i.e. $t=0$ ), as shown in equation (2):

$$
C A R_{i}=\sum_{t-2}^{t+2} A R_{i t}
$$

\subsection{Univariate analysis}

The announcement period abnormal returns of acquirers are analyzed by the methods of payment, i.e. the use of earnout $v s$. non-earnout, and by initial payment methods in earnout deals. We also analyze the cases of domestic deals $v s$. CBA deals by the methods of payment, including the cases of initial method of payment in earnout deals. We use an appropriate $t$-test to assess the statistical significance of average gains and to compare the gains of acquirers that use different methods of payment.

\subsection{Determinants of acquirers' gains: a cross-sectional analysis}

Prior studies (referenced below) show that a number of factors relating to deal features, country features, as well as the characteristics of acquirer and target firms, influence the acquirer's gains. To assess the effect of the choice of initial payment method within earnout contract, after controlling for the effects of other factors, we estimate equation (3). In particular, equation (3) is estimated in a nested regression form with various combinations of explanatory variables:

$$
C A R_{i}=\alpha+\sum_{j=1}^{k} \beta_{j} X_{i j}+\varepsilon_{i} \quad i=1 \ldots N
$$

In equation (3) the dependent variable, $C A R_{i}$, is the announcement period's cumulative excess returns of the acquirer from deal $i$ as estimated in equation (2). The intercept $(\alpha)$ measures the acquirers' excess return after accounting for the effects of a set of explanatory variables $\left(X_{i j}\right)$ discussed below. $\beta_{j}$ is a vector of the estimated coefficients of explanatory variable $X_{i j}$. The variables representing the use of earnout and the methods of initial payment in earnout deals are of main interest to us. The dummy variables that 
represent the variables of interest are: (a) 'Earnout' $=1$ if earnout is used in the financing process of the deal and 0 otherwise; (b) 'Cash Initial' $=1$ if cash is the initial payment in an earnout financed deal and 0 otherwise; (c) 'Stock Initial' = 1 if stocks are the initial payment in an earnout financed deal and 0 otherwise. To test for the possible implications of the second part payment method in earnout deals we incorporated further dummy variables. They are 'Cash deferred' $=1$ if the second part payment is in cash and 0 otherwise; 'Cash (Initial \& Deferred)' $=1$ if both the initial and second part payments are in cash and 0 otherwise; 'Stock deferred' $=1$ if the second part payment is in stock and 0 otherwise; 'Stock (Initial \& Deferred)' = 1 if both the initial and second part payments are in stocks and 0 otherwise; and 'Cash Initial \& Stock Deferred' $=1$ if initial payment is in cash and the second part payment is in stock and 0 otherwise.

Draper and Paudyal (2008) show that the announcement period returns of acquirers depend on the level of information asymmetry between managers and investors. Zhang (2006) suggests that investors tend to have more information on firms with longer trading history, leading to lower information asymmetry. Therefore, to account for the possible implications of information asymmetry, the age of the acquirer $(A G E)$, measured by the log of the number of days between the day of acquisition announcement and the date of the company's first record in Datastream, is included in equation (3). Moeller et al. (2004), among others, show that smaller acquirers gain more than larger acquirers from takeovers. Therefore, acquirers' size, measured by the log of the market value four weeks prior to the announcement of the acquisition, $(M V)$ is included in equation (3). Stulz et al. (1990) suggest that the size of the deal may affect acquirers' gains. Therefore, the log of the deal value $(D V)$ is included in equation (3). Extant literature (e.g. Fuller et al., 2002) shows that acquirers' gains are positively related to the relative size of the deal. Hence, the relative size of the deal $(R S)$, measured by the ratio of Deal Value to acquirers' Market Value four weeks prior to the announcement of the deal, is also included in equation (3). Earlier studies show that the acquirers' gains are also dependent on their growth opportunities. For instance, Rau and Vermaelen (1998) show that value acquirers (firms with a low market-to-book value ratio) outperform glamour acquirers (firms with a high market-to-book value ratio). Burch et al. (2012) find lower post-merger returns of acquirers with higher 
valuation ratios. Therefore, to control for the growth opportunity of acquirers, the ratio of market-to-book value of equity $(M T B V)$ four weeks prior to the announcement of the acquisition is included in equation (3).

Although the debate on whether corporate diversification enhances or destroys shareholders' wealth is ongoing, the literature agrees that it is likely to affect a firm's value (for a review of these studies see Sudarsanam, 2010, chapter 7). If both target and acquirer belong to the same industrial sector, the integration of the two firms may be easier and the synergy gains higher. Such deals should also benefit from the experience of the acquirer's management in managing the target's line of business, and hence generate higher excess returns. However, firms acquiring targets that operate in an unrelated business may gain from diversification, causing a reduction in the volatility of the cash flow of the combined firm and the cost of capital. Therefore, to control for the potential effect of corporate diversification, a dummy variable (DIV) that is assigned the value of 1 for diversifying deals (i.e. target and acquirer do not share the same 2-digit Standard Industrial Classification (SIC) code) and 0 for focused (FOC) deals is included in equation (3).

The valuation risk for the acquirer increases with the level of intangible assets of the target. To account for this in equation (3) we add the difficult to value dummy, which is assigned the value of 1 if the target is based in Media, Retail, High Technology, Healthcare, or Telecommunication sectors, and 0 otherwise. In some models we include dummy variables representing 'High Tech', 'Consumer Services', 'Media', 'Retail' and 'Healthcare' industries. These dummy variables take the value of 1 for the specific industry, and 0 otherwise.

Acquisitions in countries with high political stability are expected to outperform those in countries with less political stability as the acquirers of targets in the former group of countries will be able to estimate future cash flow and the merger outcomes more accurately. Therefore, a dummy variable representing the level of political stability is included in equation (3). The cultural shock of the transformation from owning/managing an independent company to running a subsidiary under the control of a larger firm may be quite traumatic for target owner-managers. The vendor managers may lack motivation or may try to 
maximize short-term profits to the detriment of the long-term interests of the acquirer. This may lead the target managers to shirking or skimping on their efforts, thereby posing moral hazard to the acquirer. Earnout contracts, therefore, need to provide monitoring and incentive mechanisms to minimize moral hazard.

However, the effectiveness of such mechanisms depends on their enforceability which, in turn, depends on the legal regime governing contract failure and remedies. Thus, avoidance of adverse selection and moral hazard depends on the appropriateness of earnout for particular M\&A deals and the enforceability of the earnout contract. The enforceability of the earnout contract in the target country should also be positively correlated with higher acquirer gains because the higher enforceability of the contract will ensure the success of the deal. Therefore, in equation (3) the enforceability of the contract is represented by another dummy variable. Finally, to account for the effects of the domiciles of the targets and the listing status of the targets, two additional dummy variables are included. The dummy variable 'CBA' takes the value of 1 if the target is not a US firm and 0 if the target is a US firm. Similarly, 'PRIV' takes the value of 1 if the target is a private firm and 0 otherwise. In addition, to assess the implications of interaction between various explanatory/control variables in shaping the gains of acquirers, several interaction variables are also included in the equation (3).

\section{The Results}

This section commences with a discussion of the results of the univariate analysis, followed by a discussion of the results from various robustness checks (including the concerns of selection biases) and those of the cross-sectional regression analysis, including the implications of the method of deferred payment in earnout deals. 


\subsection{Univariate analysis of acquirers' gains}

Table 3 presents the announcement period cumulative abnormal returns $\left(C A R_{i}\right)$ of acquirers for the full sample, as well as for sub-samples by payment methods and the target firm's domicile (domestic and foreign). The payment methods are categorized into earnout financing (grouped by the initial payment method used in earnout deals i.e. cash, stocks, combination of cash \& stocks, and others) and non-earnout financing (divided into cash only, stocks only, combination of cash \& stocks, and others). Differences in the gains between the non-earnout and earnout groups (and also sub-groupings by the initial payment method), as well as between domestic and foreign deals across all methods of payment, are computed to test the hypotheses stated in Section 2. Table 3 (Panel A) shows that on the announcement of the deal, an average acquirer makes a significant gain of $2.40 \%$ (all deals). The estimates further show that there is no significant difference in acquirers' gains from earnout (2.39\%) and non-earnout deals $(2.40 \%)$. Earnout deals, however, with an initial payment in stocks outperform the stocks only deals by $1.84 \%$ excess returns (all deals). Similarly, earnout deals with stock initial payment generate substantially higher returns than the earnout deals that are combined with cash initial payment (4.49\% vs. $1.77 \%)$. This evidence supports our first hypothesis (introduced in Section 2) that 'Acquirers that settle their purchase consideration with a combination of stocks at the first stage and earnout gain more than the acquirers that combine cash at the first stage with earnout'.

(Insert Table 3 about here)

An analysis (Table 3, Panel B) of the effect of the methods of second tranche payment shows that acquirers gain more from the deals in which the second part payment is in stocks. Moreover, the earnout deals that have both initial and second part payments in stocks gain the most (14.45\%) during the event window. This finding suggests that the payment process, which incorporates triple contingency (i.e. first stock payment, second stock payment which is contingent upon meeting the pre-set targets) plans and allows for higher levels of risk sharing, signals that the acquirer managers are committed to maximize the wealth of the shareholders and target management is confident in achieving the agreed performance 
benchmark. The cash-stock and stock-cash combinations, on the other hand, generate broadly similar returns $(8.2 \%$ and $7.6 \%)$ that are lower than in stock-stock combination $(14.45 \%)$. The cash-cash combination is the least value creating at $1.7 \%$. This suggests the need for acquirers in earnout deals to optimize the payment method combination.

The estimates (Table 3, Panel A) also show that the influence of earnout contracts on acquirers' gains is dependent on targets' domiciles. The significantly higher $(0.49 \%)$ gain observed from domestic deals, compared to that from the CBA (Table 3, domestic vs. CBA), is consistent with the findings of Moeller and Schlingemann (2005). The higher gains enjoyed by the acquirers of domestic targets come solely from the non-earnout cash financed deals $(1.36 \%)$. On the other hand, among the earnout deals, the CBA marginally outperforms the domestic deals by $1.28 \%$ excess return irrespective of initial payment method.

In the CBA, earnout deals significantly outperform the non-earnout deals $(1.69 \%$ difference in gains) while the gain difference in domestic deals (-0.27\%) is not statistically significant. Among the CBA deals, earnout deals outperform the non-earnout deals when earnouts are combined with stocks (by 12.07\%) or with stocks \& cash (by $3.37 \%$ ) in the initial payment. These results suggest that the value of the choice of the method of payment, including the choice of initial payment in earnout deals, to acquirers is also dependent on the domiciles of the targets. The higher gains from earnout deals in the CBA imply a superior contribution of the earnout contract in mitigating the valuation risk to the acquirers of foreign targets. This further support of hypothesis 1 is also reinforced by the superior gains from a combination of earnout and initial payment in stocks or a combination of cash \& stocks. In other words, acquirers gain more when the payment mechanism incorporates a higher degree of risk sharing with target owners in deals where the level of information asymmetry is likely to be higher. Specifically, the contractual commitment of the target firm's management team to meet the pre-specified goals in the post-merger period, along with the low likelihood of the acquiring firm's equity being overvalued (as is accepted by the owners/managers of privately held targets), increases the possibility of the deal's success, hence leading to higher acquirers' 
gains. This is the first ever evidence on the effect of a combination of earnout with an appropriate initial payment method on acquirers' gains, especially when the acquirers' exposure to risk is high.

The results (Table 3) further show that the method of payment in the non-earnout group, as well as the method of the initial payment in the earnout deals, significantly influence the acquirers' gains. When acquirers are exposed to significant valuation risk, they perform better when earnout is combined with stocks or a combination of cash \& stocks. This follows from our earlier argument that acquirers gain the most when their valuation risk is managed through a payment mechanism that involves more than one valuation-risk sharing tool. Therefore, our second hypothesis (introduced in Section 2): 'When the initial payment is made in stocks in earnout deals, acquirers gain more from the acquisitions of foreign targets than from the acquisitions of domestic targets.' is supported.

Overall, earnout financing appears to lessen the adverse selection risk of acquirers, as target owners are prepared to share the risk of the combined firm. A combination of earnout and stocks in the initial tranche reinforces the signal to acquirers' shareholders that target owners are even more confident about the post-merger performance of the firm as their stake is even higher. Moreover, if both initial and second part payments in earnout deals are in stocks, the acquirers gain the most. This evidence reflects the supplemental effect of stocks on to earnout contracts. The CBA carries higher adverse selection risks, hence earnout provision, along with the stock initial payment, contributes more in alleviating the potential effects of such risks. This is plausible because the combination of earnout and stocks substantially augments the contingent property incorporated in a stocks only payment (or earnout with cash initial payment) and together resolves the moral hazard and adverse selection problems by incentivizing the target firm's management to disclose any relevant information ex ante while being committed to deliver the required performance in the post-merger period. 


\subsection{Cross-sectional analysis of acquirers' gains}

Table 4 documents the estimates of multivariate analysis (equation 3) that account for the effect of several factors that are likely to affect acquirers' announcement period excess returns. As reflected in the intercepts of the models (except in model 8), after controlling for the effects of deal and firm specific factors, an average acquirer earns a significant positive excess return, confirming that an M\&A is a value enhancing venture for acquiring firms. The evidence of positive excess returns to acquirers is consistent with the findings of previous studies that include acquisitions of both listed and unlisted targets (see, for example, Faccio et al., 2006).

The results further show that earnout (the main variable of our interest), in conjunction with the combination of the method of initial payment, also affects the gains of acquirers. Estimates in models 1 and 2 suggest that, in general, earnout contracts generate lower gains to acquirers (possibly reflecting the dominance of domestic deals in the sample) but model 7 (CBA deals only) suggests the opposite. The superior performance of earnout deals (model 7) is also consistent with evidence available in the literature (see Kohers and Ang, 2000, and Barbopoulos and Sudarsanam, 2012). Further evidence (model 2) shows that acquirers of foreign targets enjoy significant gains from earnout deals. The analysis of gains by the initial method of payment used in earnout contracts provides a more reliable picture - acquirers that use earnout and settle the initial tranche in cash gain less (models 3 and 4) while acquirers that pay initially in stocks gain higher returns (models 6, 8, 9 and 11). These results corroborate our findings from the univariate analysis, i.e. that the method of an initial payment in earnout is an important factor in determining the gains to acquirers and that the highest excess returns are earned by acquirers that combine earnout with stocks. This evidence reinforces the validity of our first hypothesis. ${ }^{12}$

\footnotetext{
${ }^{12}$ Unreported results (available on request) also show that acquirers' gains from private target acquisitions increase with the portion of stock financing, suggesting that stock payment helps to reduce the potentially larger adverse selection and moral hazard risks in private targets than in public targets.
} 
The estimates in models 6 to 11 (the cases of CBA deals) further show that the possibility of legal enforcement of the contract (i.e. earnout contract) is critically important for acquirers while selecting the domiciles of targets. Estimates (models 7 and 8) suggest that acquirers using earnout contracts to acquire targets based in countries with a lower possibility of enforcing the contracts are likely to earn less, irrespective of the initial payment method. Not surprisingly, political stability in the host country is also generally positively associated with acquirers' gains (models 9 and 11), i.e. acquirers investing in countries with high political stability gain more.

The results (models 1-5) further show that, generally, acquirers' gains are affected by the listing status of the targets (acquirers of private targets gain more), the role of the domicile of targets remains neutral on acquirers' gains (models 1-5) and the impact of diversifying vs. focused deals (all models) is similar. There is also evidence (although relatively weak) that acquirers of difficult to value targets gain more than acquirers of less difficult to value targets (models 1-5) ${ }^{13}$ Consistent with the evidence in the literature, as indicated by the relative size of the deal, acquirers gain more if they are involved in larger deals (all models). Similarly, acquirers that have high growth opportunity earn more than others. On the other hand, the age of acquirers seems to have an adverse impact on their gains (models 1-5) suggesting that older acquirers gain relatively less from acquisitions.

Further analysis suggests that in private target deals acquirers' gains increase with the proportion of stock in the purchase consideration (model 12, Table 4). Similarly, model 13 suggests that in earnout deals, the proportion of stocks and acquirers' gains are positively correlated, supporting the cases of

\footnotetext{
${ }^{13}$ Additional estimates (available on request) show that acquisitions of intangible asset rich targets (such as high tech and consumer services) are associated with higher acquirer's gains. However, their interactions with either cash or stock initial payments in earnout deals appear insignificant. On the other hand, a dummy variable that captures all intangible rich sectors (i.e. difficult to value targets) is positive and significant, and its interaction with stock initial payment is also positive and significant.
} 
reduction of adverse selection and moral hazard considerations when the contact leads to higher risk sharing among the shareholders of targets and acquirers. In CBA deals (model 14) the use of a higher proportion of stocks in acquisitions of private as well as difficult to value targets leads to higher gains.

Models that control for the legal system and political stability in targets' domiciles tell a slightly different story regarding the role of some of the control factors. In such models the significance of the effects of targets' listing status, acquirers' age, acquisitions of difficult to value targets disappear - i.e. their coefficients turn statistically insignificant. Similarly, the sign of growth opportunity of acquirers turns negative (from positive), suggesting that high growth acquirers earn significantly less relative to value acquirers, which is consistent with the evidence reported by Burch et al. (2012).

(Insert Table 4 about here)

To assess the impact of additional firm-level variables relating to valuation uncertainty, information asymmetry, and moral hazard - based on the prior research (Kohers and Ang, 2000) we interact high-tech industry, service industry with the dummy variable representing stock initial, diversified and private targets. The results (Table 4, model 15) show that acquisition of targets that have high, intangible assets (e.g. high tech and consumer services) are positively associated with acquirers' gains. However, their interactions with either cash or stock initial payments in earnout deals appear insignificant. Moreover the interactions of the dummy variable representing targets from the media sector with stock initial payment (i.e. Media $\times$ Stock Initial) appear positive and significant, reflecting the importance of risk sharing in acquisitions of targets that are difficult to value. In general, the interaction of indicators of cash initial payment and private target appears negative and significant, reflecting the impact of the absence of a risk sharing component in the initial payment.

Overall, the findings suggest that, to realize the superior gains from earnout contracts, combined with a stock initial payment in CBA deals, acquirers should consider the possibility of contract enforcement and political stability in the host country as well. In other words, the evidence suggests that the ability of 
an earnout contract to reduce the adverse selection and moral hazard problems is dependent on the initial payment method used in earnout deals as well as the legal system and political stability in target nations.

\subsection{Addressing selection bias}

It is possible that the results reported above (both univariate as well as multivariate) are affected by the presence of potential selection bias as the observed gains may be because of the characteristics of the acquirers rather than due to the use of earnout per se. In experimental studies, where the two samples (the treated and control) are randomly assigned, the assessment of their comparative performance is free from such bias. However, in observational studies such as ours, the assignment is non-random and this may result in biased estimation of the treatment effect. To deal with such a concern (i.e. to reduce the vulnerability of our results to the problem of causal interpretation) we employ the Propensity Score Matching (PSM) method. PSM allows for an unbiased causal inference by pairing treated deals (earnout) with control (non-earnout) deals, based on a propensity score that is estimated at the deal level via a logit model using observable pre-treatment features. Following the matching exercise (see Dehejia and Wahba, 2002 for an application of the method) we compare the cumulative excess returns of treated and control sample deals. We estimate the propensity scores of acquirers that have used earnout and non-earnout, as well as each type of initial payment, combined with earnout $v s$. the particular single up-front payment method (for example an earnout deal that has a cash initial payment is matched with a cash only deal). We select the deals from the non-earnout group based on the alternative Matching Ratio (MR) of 1:1, 2:1 and 3:1 within 1\% Absolute Probability Difference (APD) (in the table we only report the results of MR = 1:1 to conserve space but other results, which are qualitatively similar, are available on request). To check for the accuracy of the matching process, we test whether the distributions of the covariates between the earnout 
and non-earnout (control) groups are similar. ${ }_{14}$ The test results (also available on request) confirm that the distributions of the logistic model covariates for all domestic, and CBA deals between earnout and nonearnout groups, while they are significantly different before the matching, are not statistically different after the matching. Therefore, effective matching between the treated and control samples/variables is achieved. We applied the Rosenbaum-bounds sensitivity method (Rosenbaum, 2002) to assess the effect of possible omitted variable bias that may affect the propensity score estimation and thus our findings.

(Insert Table 5 about here)

Table 5 reports the announcement period cumulative abnormal returns of acquirers for the treated (earnout) and control (non-earnout) groups of deals. Both groups of estimates (i.e. treated and control) also include gains by the method of initial payment. The final block of columns report the differentials of treated vs. control groups and sub-groupings according to the initial payment method used in earnout contracts. The estimates for the full sample show that the control group of deals generally earns significantly higher returns than the treated deals, and the same holds true for domestic deals. In the CBA, however, treated deals add significantly higher value to acquirers than the control deals, irrespective of the initial payment method. More specifically, in the CBA, significantly higher gains are earned from treated (earnout) deals

\footnotetext{
${ }^{14}$ The covariates in the logit models that we estimate include the listing status of the target (dummy = 1 if the target is private), diversified deals (dummy $=1$ if in the deal the acquirer and the target are based in different sectors, i.e. they do not share the same 2-digit code), cross-border deals (dummy $=1$ if the acquirers and the target are based in different countries), difficult to value deals (deals $=1$ if the target is based in one of the following sectors: Media, Retail, High Technology, Healthcare, and Telecommunication), log of the relative size of the deal, log of the bidding firm's age, the legal enforcement of contracts in the target country (in CBA only), the regulatory quality in the target country (in CBA only), the rule of law in the target country (in CBA only), the legal system as property rights in the target country (in CBA only), political stability in the target country (in CBA only), and year and industry fixed effects.
} 
in (a) full sample (mean difference of 2.20\%), (b) cash and earnout vs. cash only (mean difference of $2.27 \%)$, stocks and earnout vs. stocks only (15.05\%), and earnout combined with cash \& stocks vs. combination of cash \& stocks (4.62\%). These results provide clear evidence that once the effects of potential self-selection bias are addressed, the use of earnout appears even more effective in the CBA than in domestic deals. These results are also consistent with the superior performance of earnout deals in the CBA reported in Table 3, and suggest that a combination of stock and earnout is likely to mitigate adverse selection and moral hazard concerns more in CBA than domestic deals. Hence, our second hypothesis receives further support.

\section{(Insert Table 6 about here)}

We also control for the effects of potential self-selection bias in multivariate analysis. The abnormal returns of treated groups of deals are regressed against a set of explanatory variables identified earlier (equation 3) and Table 6 presents the results. The results show that the impact of earnout, as well as the impact of the initial payment in earnout financed deals on acquirers' gains, are consistent with the findings discussed in section 4.2 (Cross-sectional analysis of acquirers' gains). The effects of earnout financing on the gains from CBAs (models 6, 8, 9 and 11), the initial payment in earnout deals, the legal enforcement of contracts, and political stability, remain consistent with the results discussed in section 4.2.

The estimates in model 15 (Table 6) show that the interaction between targets with intangible assets and payment of the initial tranche in cash (Consumer Services $\times$ Cash Initial) is negative and marginally significant. Similar to the evidence documented in Table 4, the interaction of the dummy variable representing targets in the media sector with stock initial payment (i.e. Media $\times$ Stock Initial) is positive and marginally significant. This reconfirms the importance of risk sharing in acquisitions of targets that are based in this difficult to value sector. Further, the dummy capturing all intangible asset rich sectors (i.e. difficult to value) as well as its interaction with stock initial payment are positive and significant (model 13) indicating that, on balance, acquirers gain more if earnout contracts are used in the acquisitions of difficult to value targets (model 13). 
The results, which are robust to self-selection bias tests, suggest that acquirers gain the most from earnout deals in CBAs and the magnitude of the gain is also dependent on the choice of initial payment in earnout deals. The results further suggest that risk sharing is more beneficial in the presence of higher information asymmetry, where the need for mitigating the adverse selection and moral hazard problems is more meaningful. Consequently, from the acquirers' perspective, earnout provision, combined with stocks payment in the initial tranche, seems to be the most effective form of payment in the CBA.

\subsection{Initial and second part payments in earnout finance deals}

The above analysis (sections 4.1 to 4.3 ) on the impact of the choice of initial payment method in earnout deals implicitly assumes that the method of second part payment is either identical in all deals or the impact is trivial. However, as noted earlier in the paper, all deals neither use the same method of payment in the second tranche (see footnote 3 ) nor are the effects likely to be similar as the risk sharing can vary by method of payment. Therefore, we extend our analysis to examine the consequences of the methods of second part payment, in conjunction with the method of initial payment, on acquirers' gains from earnout deals. Logically, use of a combination of cash (stock) in the initial payment and cash (stock) in the second part in earnout deals is similar to a cash (stock) financed deal, with the exception that the payment of the second part of total purchase consideration is contingent upon the target firm meeting the pre-determined performance milestones within a specified time. Similarly, the choice of the method of second part payment may also set alternative expectations relative to the full up-front payment in cash or in stock.

\section{(Insert Table 7 about here)}

The estimates (Table 7) suggest that acquirers' abnormal returns are significantly higher in earnout deals in which the second part payment is in stock (models 4 to 6 ) rather than in cash (models 1 to 3 ). Note that in the two sets of models the initial payment was in cash and stock, respectively. Consequently, the deals are settled either in cash (both initial and second part payment) or in stock (both initial and second part payment). The evidence of significantly higher gains from earnout deals in which both initial and 
second part payment are in stock suggests that the choice of the second part payment method is far from trivial for acquirers. Model 3 also reveals that when both the initial and second part payments in CBA are stock, acquirers make significant gains. However, if both tranches are in cash they suffer small losses (model 6). Models 7 and 8 provided further support to this evidence.

Finally, the decision to settle the second part payment in stock, when the first payment is in cash, offers an interesting alternative. It suggests that the settlement of the earnout in stock leads to a more calibrated contract design that is associated with a higher possibility of merger success (models 9 to 11). Overall, the findings suggest that the decision to pay the second tranche in stock is associated with higher gains, irrespective of the method of the initial payment in earnout deals.

\section{Conclusions}

This paper examines the impact of the initial payment method used in earnout deals to US acquirers. This is the first study to: (a) investigate the implications of an initial and deferred payment in earnout financed deals on the gains of acquirers in domestic and foreign deals; (b) address the potential effects of self-selection bias that may reduce the reliability of initial findings by employing the PSM based on several firm-, transaction-, and country-specific characteristics; and (c) consider the impact of political stability, as well as the level of contract enforcement embedded in the legal regimes of the target firms' domicile as a safeguard against moral hazard when earnout is used. The results, which are robust to model specifications as well as potential self-selection bias, show that acquirers of foreign targets enjoy significant gains when earnout is included in purchase considerations.

Moreover, we find that earnout deals outperform non-earnout deals when earnout is combined with stocks or with cash \& stocks. The CBAs financed with such combinations outperform similarly financed domestic deals. Such evidence suggests that earnout delivers its designated risk-mitigating advances only when the contingencies of the choice of the initial payment are similar to those of earnout. Further, supporting the view that higher risk sharing helps more in mitigating the implications of information 
asymmetry, our results suggest that initial payment in stock followed by a second payment in stock can generate superior returns to acquirers. Therefore, the use of earnout provides an effective mechanism for mitigating the adverse selection and moral hazard problems when it is combined with an appropriate initial and second part payment method that maximizes risk sharing between the merging partners.

The findings emphasize the importance of combining earnout with the appropriate initial payment, second part payment as well as considering the various characteristics encompassing the takeover bid, acquirer and target firms, political stability, and the legal enforcement in which the earnout contract will be written and enforced. Overall, our findings suggest that in deals where there are higher risks of adverse selection and moral hazard, the use of the payment method that is contingent upon post-acquisition performance of targets can add higher value to the wealth of the shareholders of acquiring firms. 
Appendix A: The variables and their definitions

This table summarizes the variables used in the paper along with their data sources. SDC is Thomson-Reuters' SDC database. Industries are grouped following SDC classification. Variables Age, RS, MV, and DV are log transformed in both logistic and OLS regressions.

\begin{tabular}{|c|c|c|}
\hline Variables & Description & Data Source \\
\hline Acquirers' CAR & $\begin{array}{l}\text { Acquiring firm's announcement period cumulative abnormal return. } \\
\text { Estimated using equations (1) and (2). }\end{array}$ & Datastream \\
\hline Acq. Age & $\begin{array}{l}\text { Acquirer's age, measured between day the acquirer is first recorded on } \\
\text { Datastream and acquisition announcement day. }\end{array}$ & Datastream/SDC \\
\hline ALL & Full sample of the deals. & Datastream \\
\hline Cash & $\begin{array}{l}\text { Deals that are settled in cash only. Dummy variable takes the value of } 1 \\
\text { when } 100 \% \text { of deal consideration is paid in cash, and }=0 \text { otherwise. }\end{array}$ & SDC \\
\hline Cash Deferred & $\begin{array}{l}\text { Earnout deals with deferred payment in cash. Assigned the value of } 1 \text { if } \\
\text { cash is the deferred payment in earnout deals and }=0 \text { otherwise. }\end{array}$ & $\begin{array}{l}8-\mathrm{K} \text { and } 10-\mathrm{K} \\
\text { EDGAR filings }\end{array}$ \\
\hline Cash Initial & $\begin{array}{l}\text { Earnout deals with cash initial payment. Assigned the value of } 1 \text { if cash } \\
\text { is the initial payment in earnout deals and }=0 \text { otherwise. }\end{array}$ & SDC \\
\hline$\%$ of cash & Refers to the percentage of the cash in total value of the deal. & SDC \\
\hline $\mathrm{CBA}$ & $\begin{array}{l}\text { Cross-border mergers and acquisitions, i.e. deals involving foreign } \\
\text { targets. }\end{array}$ & SDC \\
\hline Combo & $\begin{array}{l}\text { Deals that are settled in a combination of 'Cash \& Stocks' only. Dummy } \\
\text { variable takes the value of } 1 \text { when } 100 \% \text { of deal consideration is paid in } \\
\text { combo, and }=0 \text { otherwise. }\end{array}$ & SDC \\
\hline Combo Initial & $\begin{array}{l}\text { Earnout deals with combo initial payment. Assigned the value of } 1 \text { if } \\
\text { combo is the initial payment in earnout deals and }=0 \text { otherwise. }\end{array}$ & SDC \\
\hline $\begin{array}{r}\text { Consumer } \\
\text { Services }\end{array}$ & $\begin{array}{l}\text { Consumer Services Dummy }=1 \text {, and }=0 \text { otherwise, refers to deals in } \\
\text { which the targets operate in the consumer services industry. }\end{array}$ & SDC \\
\hline DIFFVL & $\begin{array}{l}\text { Difficult to Value Sectors. Dummy variable takes the value of } 1 \text { if the } \\
\text { target firm operates in Media, Retail, High Technology, Healthcare, or } \\
\text { Telecommunications sectors, and }=0 \text { otherwise. }\end{array}$ & SDC \\
\hline DIV & $\begin{array}{l}\text { Diversifying deals. Dummy }=1 \text { when acquirer and target do not share } \\
\text { the same SIC code (2-digit) and }=0 \text { when they share }(=\text { FOC). }\end{array}$ & SDC \\
\hline DOM & Deals involving domestic targets. & SDC \\
\hline DV & Acquisition transactions value (in million US dollars). & SDC \\
\hline Earnout & $\begin{array}{l}\text { Earnout deals. Assigned the value of } 1 \text { when purchase consideration } \\
\text { includes Earnout, and }=0 \text { otherwise (= Non Earnout i.e. the deals that } \\
\text { are financed with single up-front payments). }\end{array}$ & SDC \\
\hline Earnout value & Value of earnout in earnout deals (in million US dollars). & SDC \\
\hline$\%$ of earnout & Refers to the percentage of earnout component in total value of the deal. & SDC \\
\hline Healthcare & $\begin{array}{l}\text { Healthcare Dummy }=1 \text {, and }=0 \text { otherwise, refers to deals in which the } \\
\text { targets operate in the healthcare industry. }\end{array}$ & SDC \\
\hline High Tech & $\begin{array}{l}\text { High Tech Dummy }=1 \text {, and }=0 \text { otherwise, refers to deals in which the } \\
\text { targets operate in high technology industry. }\end{array}$ & SDC \\
\hline
\end{tabular}

Continued 
Appendix A (Continued)

\begin{tabular}{|c|c|c|}
\hline Variables & Description & Data Source \\
\hline $\mathrm{LS}$ & $\begin{array}{l}\text { The legal enforcement of contracts in the target's country. Since the } \\
\text { information on legal enforcement of contracts is available only annually, } \\
\text { M\&A deals announced before (after) June are matched with the legal } \\
\text { enforcement of contracts of the previous (same) year. }\end{array}$ & $\begin{array}{l}\frac{\text { Www.freetheworl }}{\text { d.com }} \\
\text { Fraser Institute }\end{array}$ \\
\hline Media & $\begin{array}{l}\text { Media Dummy }=1 \text {, and }=0 \text { otherwise, refers to deals in which the targets } \\
\text { operate in media and entertainment industry. }\end{array}$ & SDC \\
\hline MTBV & $\begin{array}{l}\text { Market-to-Book Value ratio of acquirer. Market value (MV) is four } \\
\text { weeks before the announcement while book value of equity is from the } \\
\text { most recent accounting statement prior to acquisition announcement. }\end{array}$ & Datastream \\
\hline MV & $\begin{array}{l}\text { Acquirer's market value four weeks prior to the announcement of deal } \\
\text { (in million US dollars). }\end{array}$ & Datastream \\
\hline Other & $\begin{array}{l}\text { Deals that are settled in a combination of multiple securities other than } \\
\text { cash, stocks, or combo. Dummy variable takes the value of } 1 \text { when } 100 \% \\
\text { of deal consideration is paid in other, and = } 0 \text { otherwise. }\end{array}$ & SDC \\
\hline Other Initial & $\begin{array}{l}\text { Earnout deals with other initial payment. Assigned the value of } 1 \text { if other } \\
\text { is the initial payment in earnout deals and }=0 \text { otherwise. }\end{array}$ & SDC \\
\hline Private & $\begin{array}{l}\text { Deals in which targets are private. Dummy variable takes the value of } 1 \\
\text { if the target is private and }=0 \text { otherwise. }\end{array}$ & SDC \\
\hline PS & $\begin{array}{l}\text { Political Stability. It measures perceptions of the likelihood of political } \\
\text { instability and/or politically motivated violence, including terrorism. }\end{array}$ & $\begin{array}{l}\text { Worldwide } \\
\text { Governance } \\
\text { Indicators }\end{array}$ \\
\hline Public & $\begin{array}{l}\text { Deals in which targets are public. Dummy variable takes the value of } 1 \\
\text { if the target is public and }=0 \text { otherwise. }\end{array}$ & SDC \\
\hline REAV & The ratio of earnout value (EA) to deal value (DV) in earnout deals. & SDC \\
\hline Retail & $\begin{array}{l}\text { Retail Dummy }=1 \text {, and }=0 \text { otherwise, refers to deals in which the targets } \\
\text { operate in the retail industry. }\end{array}$ & SDC \\
\hline $\mathrm{RS}$ & $\begin{array}{l}\text { Relative deal size, i.e. ratio of deal value (DV) to market value (MV) of } \\
\text { acquirer four weeks before the announcement of deal. }\end{array}$ & $\begin{array}{l}\text { Datastream + } \\
\text { SDC }\end{array}$ \\
\hline Stocks & $\begin{array}{l}\text { Deals that are settled in stocks only. Dummy variable takes the value of } \\
1 \text { when } 100 \% \text { of deal consideration is paid in stocks, and }=0 \text { otherwise. }\end{array}$ & SDC \\
\hline Stock Initial & $\begin{array}{l}\text { Earnout deals with stock initial payment. Assigned the value of } 1 \text { if stock } \\
\text { is the initial payment in earnout deals and }=0 \text { otherwise. }\end{array}$ & SDC \\
\hline Stock Deferred & $\begin{array}{l}\text { Earnout deals with stock deferred payment. Assigned the value of } 1 \text { if } \\
\text { stock is the deferred payment in earnout deals and }=0 \text { otherwise. }\end{array}$ & $\begin{array}{l}8-\mathrm{K} \text { and } 10-\mathrm{K} \\
\text { EDGAR filings }\end{array}$ \\
\hline$\%$ of stock & Refers to the percentage of the stock payment in total deal value. & SDC \\
\hline Subsidiary & Deals involving acquisitions of subsidiaries. & SDC \\
\hline
\end{tabular}




\section{References}

Barbopoulos, L., and S. Sudarsanam, 2012, Determinants of earnout as acquisition payment currency and bidders' value gains, Journal of Banking and Finance 36, 678-694.

Brown, S., and J. Warner, 1980, Measuring security price performance, Journal of Financial Economics 8, 205-258.

Burch, T. R., V. Nanda, and S. Silveri, 2012, Do institutions prefer high-value acquirers? An analysis of trading in stock-financed acquisitions, Journal of Financial Research 35, 211-241.

Cain, M. D., D. J. Denis, and D. K. Denis, 2011, Earnouts: A study of financial contracting in acquisition agreements, Journal of Accounting and Economics 51, 151-170.

Datar, S., R. Frankel, and M. Wolfson, 2001, Earnouts: The effects of adverse selection and agency costs on acquisition techniques, The Journal of Law, Economics and Organization 17, 201-238.

Dehejia, R.H., and S. Wahba, 2002, Propensity score-matching methods for non-experimental causal studies, The Review of Economics and Statistics 84, 151-161.

Draper, P., and K. Paudyal, 2008, Information asymmetry and acquirers' gains, Journal of Business Finance and Accounting 35, 376-405.

Eckbo, B. E., R. M. Giammarino, and L. R. Heinkel, 1990, Asymmetric information and the medium of exchange in takeovers: Theory and tests, The Review of Financial Studies 3, 651-675.

Faccio, M., and R. W. Masulis, 2005, The choice of payment method in European mergers and acquisitions, Journal of Finance 60, 1345-1388.

Faccio, M., J. J. McConnell, and D. Stolin, 2006, Returns to acquirers of listed and unlisted targets, Journal of Financial and Quantitative Analysis 41, 197-220.

Fuller, K., J. Netter, and M. Stegemoller, 2002, What do returns to acquiring firms tell us? Evidence from firms that make many acquisitions, Journal of Finance 57, 1763-1793.

Hansen, R. S., 1987, A theory for the choice of exchange medium in mergers and acquisitions, Journal of Business 60, 75-95. 
Kohers, N., and J. Ang, 2000, Earnouts in mergers and acquisitions: Agreeing to disagree and agreeing to stay, Journal of Business 73, 445-476.

Moeller, S. B., and F. P. Schlingemann, 2005, Global Diversification and acquirer gains: A comparison between cross-border and domestic acquisitions, Journal of Banking and Finance 29, 533-564.

Moeller, S. B., F. P. Schlingemann, and R. M. Stulz, 2004, Firm size and gains from acquisitions, Journal of Financial Economics 73, 201-228.

Rau, R. P., and T. Vermaelen, 1998, Glamour, value and the post-acquisition performance of acquiring firms, Journal of Financial Economics 49, 223-253.

Reuer, J., O. Shenkar, and R. Ragozzino, 2004, Mitigating risk in international mergers and acquisitions: the role of contingent payouts, Journal of International Business Studies 35, 19-32.

Rosenbaum, P. R., 2002, Design of observational studies (Springer series in statistics).

Stulz, R. M., A. R. Walkling, and M. H. Song, 1990, The distribution of target ownership and the division of gains in successful takeovers, Journal of Finance 45, 817-833.

Sudarsanam, S., 2010, Creating Value from Mergers and Acquisitions: The Challenges (Pearson Education Limited, London).

White, H., 1980, A heteroscedasticity-consistent covariance matrix estimator and a direct test for heteroscedasticity, Econometrica 48, 817-838.

Zhang, F.X., 2006, Information uncertainty and stock returns, Journal of Finance 6, 105-135. 
Table 1: Annual Distribution of Sample Deals and their Features

This table presents the annual distribution of M\&A activities in the US between 01/01/1986 and 31/12/2013 by methods of payments in general as well as by the methods of initial payments in earnout deals. The definitions of the variables can be found in Appendix A.

\begin{tabular}{|c|c|c|c|c|c|c|c|c|c|c|c|c|c|c|}
\hline \multirow[b]{2}{*}{ Year } & \multirow[b]{2}{*}{ ALL deals } & \multirow[b]{2}{*}{ DOM } & \multirow[b]{2}{*}{ CBA } & \multicolumn{5}{|c|}{ Non-earnout deals by methods of payment } & \multicolumn{5}{|c|}{ Earnout deals by methods of initial payment } & \multirow[b]{2}{*}{$\begin{array}{c}\text { Acquirers' } \\
\text { CAR }\end{array}$} \\
\hline & & & & Total deals & Cash & Stocks & Combo & Other & Earnout & $\begin{array}{l}\text { Cash } \\
\text { Initial }\end{array}$ & $\begin{array}{l}\text { Stock } \\
\text { Initial }\end{array}$ & $\begin{array}{c}\text { Combo } \\
\text { Initial }\end{array}$ & $\begin{array}{l}\text { Other } \\
\text { Initial }\end{array}$ & \\
\hline 1986 & 330 & 323 & 7 & 324 & 221 & 46 & 45 & 12 & 6 & 4 & 0 & 0 & 2 & 1.97 \\
\hline 1987 & 402 & 391 & 11 & 392 & 286 & 50 & 49 & 7 & 10 & 3 & 1 & 4 & 2 & 1.61 \\
\hline 1988 & 440 & 426 & 14 & 432 & 309 & 51 & 64 & 8 & 8 & 2 & 1 & 2 & 3 & 2.30 \\
\hline 1989 & 647 & 615 & 32 & 620 & 447 & 81 & 77 & 15 & 27 & 11 & 2 & 4 & 10 & 1.37 \\
\hline 1990 & 718 & 692 & 26 & 697 & 544 & 73 & 68 & 12 & 21 & 11 & 3 & 2 & 5 & 2.12 \\
\hline 1991 & 510 & 457 & 53 & 471 & 258 & 94 & 99 & 20 & 39 & 12 & 9 & 7 & 11 & 3.28 \\
\hline 1992 & 800 & 732 & 68 & 763 & 424 & 147 & 176 & 16 & 37 & 15 & 7 & 4 & 11 & 3.05 \\
\hline 1993 & 947 & 890 & 57 & 874 & 475 & 192 & 189 & 18 & 73 & 21 & 10 & 16 & 26 & 2.88 \\
\hline 1994 & 1,303 & 1,211 & 92 & 1,242 & 720 & 235 & 272 & 15 & 61 & 21 & 13 & 16 & 11 & 2.76 \\
\hline 1995 & 1,488 & 1,364 & 124 & 1,426 & 801 & 314 & 293 & 18 & 62 & 21 & 10 & 12 & 19 & 2.26 \\
\hline 1996 & 1,814 & 1,689 & 125 & 1,749 & 947 & 420 & 367 & 15 & 65 & 26 & 8 & 10 & 21 & 2.52 \\
\hline 1997 & 2,103 & 1,941 & 162 & 2,004 & 1,056 & 416 & 512 & 20 & 99 & 33 & 10 & 18 & 38 & 2.16 \\
\hline 1998 & 2,652 & 2,411 & 241 & 2,530 & 1,584 & 406 & 517 & 23 & 122 & 49 & 12 & 31 & 30 & 2.51 \\
\hline 1999 & 2,172 & 1,985 & 187 & 2,090 & 1,230 & 476 & 366 & 18 & 82 & 26 & 16 & 18 & 22 & 3.24 \\
\hline 2000 & 1,865 & 1,675 & 190 & 1,762 & 834 & 552 & 352 & 24 & 103 & 32 & 25 & 20 & 26 & 2.34 \\
\hline 2001 & 1,218 & 1,088 & 130 & 1,132 & 633 & 249 & 238 & 12 & 86 & 28 & 19 & 23 & 16 & 3.53 \\
\hline 2002 & 1,040 & 907 & 133 & 949 & 590 & 131 & 217 & 11 & 91 & 39 & 17 & 16 & 19 & 3.15 \\
\hline 2003 & 945 & 849 & 96 & 855 & 560 & 113 & 178 & 4 & 90 & 46 & 10 & 19 & 15 & 3.16 \\
\hline 2004 & 1,139 & 989 & 150 & 1,037 & 718 & 97 & 214 & 8 & 102 & 45 & 7 & 22 & 28 & 1.49 \\
\hline 2005 & 1,212 & 1,059 & 153 & 1,118 & 812 & 85 & 211 & 10 & 94 & 46 & 2 & 22 & 24 & 1.85 \\
\hline 2006 & 1,110 & 977 & 133 & 1,012 & 774 & 54 & 176 & 8 & 98 & 55 & 8 & 20 & 15 & 1.65 \\
\hline 2007 & 1,196 & 1,068 & 128 & 1,094 & 887 & 56 & 147 & 4 & 102 & 67 & 6 & 14 & 15 & 1.94 \\
\hline 2008 & 1,084 & 983 & 101 & 1,022 & 881 & 37 & 97 & 7 & 62 & 43 & 4 & 10 & 5 & 2.27 \\
\hline 2009 & 566 & 482 & 84 & 504 & 398 & 37 & 64 & 5 & 62 & 31 & 5 & 13 & 13 & 2.99 \\
\hline 2010 & 724 & 624 & 100 & 657 & 554 & 29 & 69 & 5 & 67 & 45 & 3 & 7 & 12 & 1.62 \\
\hline 2011 & 855 & 755 & 100 & 790 & 671 & 30 & 87 & 2 & 65 & 41 & 7 & 6 & 11 & 1.22 \\
\hline 2012 & 719 & 604 & 115 & 655 & 558 & 16 & 81 & 0 & 64 & 39 & 1 & 9 & 15 & 2.17 \\
\hline 2013 & 554 & 478 & 76 & 510 & 430 & 21 & 58 & 1 & 44 & 30 & 3 & 5 & 6 & 1.72 \\
\hline Total & 30,553 & 27,665 & 2,888 & 28,711 & 18,602 & 4,508 & 5,283 & 318 & 1,842 & 842 & 219 & 350 & 431 & - \\
\hline$\%$ of All & - & 90.5 & 9.5 & 94.0 & 60.9 & 14.8 & 17.3 & 1.0 & 6.0 & 2.8 & 0.7 & 1.1 & 1.4 & - \\
\hline
\end{tabular}


Table 2: Summary Statistics

This table presents the summary statistics of our sampled deals by their key features. The mean values are in $\$$ million and $\mathrm{N}$ refers to the number of deals. The sample is comprised of acquisitions announced by US firms between 01/01/1986 and 31/12/2013 that meet the criteria summarized in section 3.1. The definitions of the variables can be found in Appendix A.

Panel A

\begin{tabular}{|c|c|c|c|c|c|c|c|c|c|c|c|c|c|c|c|c|}
\hline & & \multirow[b]{2}{*}{$\begin{array}{c}\text { All } \\
\text { Deals }\end{array}$} & \multicolumn{5}{|c|}{ Non-earnout (NEA) deals } & \multicolumn{5}{|c|}{ Earnout (EA) deals } & \multicolumn{2}{|c|}{ Domicile } & \multicolumn{2}{|c|}{ Diversity } \\
\hline & & & $\begin{array}{c}\text { Non } \\
\text { Earnout }\end{array}$ & Cash & Stocks & Combo & Other & Earnout & $\begin{array}{l}\text { Cash } \\
\text { Initial }\end{array}$ & $\begin{array}{l}\text { Stock } \\
\text { Initial }\end{array}$ & $\begin{array}{c}\text { Combo } \\
\text { Initial }\end{array}$ & $\begin{array}{l}\text { Other } \\
\text { Initial }\end{array}$ & DOM & CBA & FOC & DIV \\
\hline \multirow{3}{*}{ All } & Mean $M V$ & 5,686 & 5,846 & 6,862 & 5,470 & 2,744 & 3,282 & 3,198 & 4,837 & 2,045 & 829 & 2,507 & 5,254 & 9,833 & 5,110 & 7,220 \\
\hline & Mean DV & 338 & 353 & 282 & 406 & 559 & 307 & 102 & 120 & 80 & 75 & 99 & 350 & 225 & 367 & 260 \\
\hline & $N$ & 30,553 & 28,711 & 18,602 & 4,508 & 5,283 & 318 & 1,842 & 842 & 219 & 350 & 431 & 27,665 & 2,888 & 22,208 & 8,345 \\
\hline \multirow{4}{*}{ Private } & Mean $M V$ & 3,791 & 3,976 & 6,209 & 4,595 & 1,192 & 655 & 2,649 & 3,958 & 2,296 & 819 & 2,021 & 3,459 & 5,897 & 2,760 & 5,089 \\
\hline & Mean DV & 77 & 75 & 85 & 63 & 79 & 27 & 86 & 99 & 85 & 60 & 86 & 76 & 82 & 86 & 65 \\
\hline & $N$ & 9,843 & 8470 & 2,950 & 2,600 & 2,798 & 122 & 1,373 & 596 & 178 & 284 & 315 & 8,502 & 1,341 & 5,487 & 4,356 \\
\hline & $\%$ of All & 32.22 & 29.50 & 15.86 & 57.68 & 52.96 & 38.36 & 74.54 & 70.78 & 81.28 & 81.14 & 73.09 & 30.73 & 46.43 & 24.71 & 52.20 \\
\hline \multirow{4}{*}{ Public } & Mean $M V$ & 7,063 & 7,060 & 6,955 & 8,225 & 6,986 & 5,230 & 7,802 & 20,617 & 1,698 & 2,749 & 1,534 & 6,663 & 17,566 & 6,098 & 14,856 \\
\hline & Mean DV & 543 & 544 & 348 & 1,142 & 2,047 & 460 & 207 & 183 & 109 & 463 & 111 & 543 & 555 & 500 & 889 \\
\hline & $N$ & 15,474 & 15,426 & 12,796 & 1,400 & 1,120 & 110 & 48 & 15 & 15 & 10 & 8 & 14,907 & 567 & 13,770 & 1,704 \\
\hline & $\%$ of All & 50.65 & 53.73 & 68.79 & 31.06 & 21.20 & 34.59 & 2.61 & 1.78 & 6.85 & 2.86 & 1.86 & 53.88 & 19.63 & 62.00 & 20.42 \\
\hline \multirow{4}{*}{ Subsidiary } & Mean $M V$ & 5,183 & 5,246 & 7,120 & 2,361 & 2,446 & 4,516 & 4,465 & 6,078 & 528 & 537 & 3,997 & 3,902 & 10,746 & 4,870 & 5,587 \\
\hline & Mean DV & 222 & 229 & 193 & 134 & 323 & 510 & 141 & 170 & 30 & 82 & 138 & 221 & 228 & 268 & 164 \\
\hline & $N$ & 5,236 & 4,815 & 2,856 & 508 & 1,365 & 86 & 421 & 231 & 26 & 56 & 108 & 4,256 & 980 & 2,951 & 2,285 \\
\hline & $\%$ of All & 17.14 & 16.77 & 15.35 & 11.27 & 25.84 & 27.04 & 22.86 & 27.43 & 11.87 & 16.00 & 25.06 & 15.38 & 33.93 & 13.29 & 27.38 \\
\hline
\end{tabular}




\begin{tabular}{|c|c|c|c|c|c|c|c|c|c|c|c|c|}
\hline & \multirow[b]{2}{*}{$N$} & \multirow{2}{*}{$\begin{array}{c}\text { Market Value } \\
(M V)\end{array}$} & \multirow{2}{*}{$\begin{array}{c}\text { Deal Value } \\
(D V) \\
\text { Mean }\end{array}$} & \multirow{2}{*}{$\begin{array}{c}\text { Relative Size } \\
(R S) \\
\text { Mean }\end{array}$} & \multicolumn{2}{|c|}{ Earnout Value } & \multicolumn{2}{|c|}{$\begin{array}{c}\text { Relative earnout Value } \\
(\text { REAV) }\end{array}$} & \multicolumn{2}{|c|}{$\begin{array}{c}\text { Market-to-Book Value } \\
(M T B V)\end{array}$} & \multicolumn{2}{|c|}{ Acquirer Age (in years } \\
\hline & & & & & $N$ & Mean & $N$ & Mean & $N$ & Mean & $N$ & Mean \\
\hline All & 30,553 & 5,686 & 338 & 55 & 1,685 & 29 & 1,685 & 34 & 27,557 & 3.3 & 30,542 & 12.9 \\
\hline Domestic & 27,665 & 5,254 & 350 & 56 & 1,399 & 28 & 1,399 & 34 & 24,929 & 3.4 & 27,654 & 12.7 \\
\hline Cross-border & 2,888 & 9,833 & 225 & 46 & 286 & 34 & 286 & 33 & 2,628 & 2.0 & 2,888 & 14.3 \\
\hline Focused & 22,208 & 5,110 & 367 & 36 & 983 & 38 & 983 & 34 & 20,261 & 4.5 & 22,200 & 13.1 \\
\hline Diversified & 8,345 & 7,220 & 260 & 105 & 702 & 17 & 702 & 33 & 7,296 & 0.0 & 8,342 & 12.3 \\
\hline Non Earnout & 28,711 & 5,846 & 353 & 57 & - & - & - & - & 25,926 & 3.4 & 28,700 & 13.0 \\
\hline Cash & 18,602 & 6,862 & 282 & 33 & - & - & - & - & 17,360 & 2.9 & 18,596 & 15.0 \\
\hline Stocks & 4,508 & 5,470 & 406 & 70 & - & - & - & - & 3,803 & 6.8 & 4,505 & 7.9 \\
\hline Combo & 5,283 & 2,744 & 559 & 130 & - & - & - & - & 4,527 & 2.3 & 5,281 & 10.1 \\
\hline Other & 318 & 3,282 & 307 & 74 & - & - & - & - & 236 & 3.9 & 318 & 10.4 \\
\hline Earnout & 1,842 & 3,198 & 102 & 26 & 1,685 & 29 & 1,685 & 34 & 1,631 & 1.9 & 1,842 & 11.4 \\
\hline Cash Initial & 842 & 4,837 & 120 & 18 & 805 & 33 & 805 & 32 & 777 & 2.6 & 842 & 14.1 \\
\hline Stock Initial & 219 & 2,045 & 80 & 50 & 209 & 23 & 209 & 40 & 168 & -6.3 & 219 & 8.0 \\
\hline Combo Initial & 350 & 829 & 75 & 30 & 273 & 19 & 273 & 30 & 311 & 2.8 & 350 & 8.7 \\
\hline Other Initial & 431 & 2,507 & 99 & 26 & 398 & 33 & 398 & 37 & 375 & 3.1 & 431 & 10.1 \\
\hline Private & 9,843 & 3,791 & 77 & 38 & 1,251 & 29 & 1,251 & 34 & 8,562 & 5.0 & 9,839 & 9.7 \\
\hline Public & 15,474 & 7,063 & 543 & 65 & 44 & 51 & 44 & 31 & 14,314 & 3.1 & 15,468 & 14.8 \\
\hline Subsidiary & 5,236 & 5,183 & 222 & 56 & 390 & 28 & 390 & 33 & 4,681 & 0.8 & 5,235 & 12.9 \\
\hline
\end{tabular}


Table 3: Acquirers' announcement period returns: Univariate analysis

This table presents the announcement period, 5-days [-2, +2], abnormal returns (in \%) of all deals measured by equation (2). The deals are grouped by the target firm's domicile, by methods of payment in general and initial payment (Panel A) in earnout deals, and the differences in gains from domestic and Cross-border deals are presented. Implications of second part payment on CAR of acquirers are presented in panel B. $N$ refers to the number of observations in each portfolio and Appendix A provides the definitions of the variables. $\mathrm{a}, \mathrm{b}$, and c indicate significance at $1 \%, 5 \%$ and $10 \%$ respectively.

Panel A: Gains from earnout vs. non-earnout deals by method of initial payment.

\begin{tabular}{|c|c|c|c|c|c|c|c|c|c|c|c|c|c|c|c|c|}
\hline & \multirow[b]{2}{*}{ ALL Deals } & \multicolumn{5}{|c|}{ Non-Earnout (NEA) deals } & \multicolumn{5}{|c|}{ Earnout (EA) deals } & \multirow{2}{*}{$\begin{array}{c}\text { Earnout } \\
\text { vs. } \\
\text { Non } \\
\text { Earnout }\end{array}$} & \multirow{2}{*}{$\begin{array}{c}\text { Cash } \\
\text { Initial } \\
\text { vs. } \\
\text { Cash }\end{array}$} & \multirow{2}{*}{$\begin{array}{c}\text { Stock } \\
\text { Initial } \\
\text { vs. } \\
\text { Stocks }\end{array}$} & \multirow{2}{*}{$\begin{array}{c}\text { Combo } \\
\text { Initial } \\
\text { vs. } \\
\text { Combo }\end{array}$} & \multirow{2}{*}{$\begin{array}{c}\text { Other } \\
\text { Initial } \\
\text { vs. } \\
\text { Other }\end{array}$} \\
\hline & & $\begin{array}{c}\text { Non } \\
\text { Earnout }\end{array}$ & Cash & Stocks & Combo & Other & Earnout & $\begin{array}{l}\text { Cash } \\
\text { Initial }\end{array}$ & $\begin{array}{l}\text { Stock } \\
\text { Initial }\end{array}$ & $\begin{array}{c}\text { Combo } \\
\text { Initial }\end{array}$ & $\begin{array}{l}\text { Other } \\
\text { Initial }\end{array}$ & & & & & \\
\hline \multicolumn{17}{|c|}{ All deals } \\
\hline Mean & $2.40^{\mathrm{a}}$ & $2.40^{\mathrm{a}}$ & $2.22^{\mathrm{a}}$ & $2.65^{\mathrm{a}}$ & $2.75^{\mathrm{a}}$ & $3.46^{\mathrm{a}}$ & $2.39^{\mathrm{a}}$ & $1.77^{\mathrm{a}}$ & $4.49^{\mathrm{a}}$ & $3.46^{\mathrm{a}}$ & $1.68^{\mathrm{a}}$ & -0.01 & -0.45 & $1.84^{\mathrm{c}}$ & 0.71 & $-1.78^{b}$ \\
\hline Median & $1.16^{\mathrm{a}}$ & $1.19^{\mathrm{a}}$ & $1.29^{\mathrm{a}}$ & $0.45^{\mathrm{a}}$ & $1.23^{\mathrm{a}}$ & $1.17^{\mathrm{a}}$ & $0.89^{\mathrm{a}}$ & $0.62^{\mathrm{a}}$ & $1.74^{\mathrm{b}}$ & $1.67^{\mathrm{a}}$ & $0.74^{\mathrm{c}}$ & -0.29 & $-0.67^{b}$ & $1.28^{\mathrm{b}}$ & 0.43 & -0.44 \\
\hline $\mathrm{N}$ & 30,553 & 28,711 & 18,602 & 4,508 & 5,283 & 318 & 1,842 & 842 & 219 & 350 & 431 & & & & & \\
\hline \multicolumn{17}{|c|}{ Domestic deals (DOM) } \\
\hline Mean & $2.44^{\mathrm{a}}$ & $2.46^{\mathrm{a}}$ & $2.33^{\mathrm{a}}$ & $2.68^{\mathrm{a}}$ & $2.70^{\mathrm{a}}$ & $3.33^{\mathrm{a}}$ & $2.19^{\mathrm{a}}$ & $1.79^{\mathrm{a}}$ & $3.15^{\mathrm{a}}$ & $3.00^{\mathrm{a}}$ & $1.75^{\mathrm{a}}$ & -0.27 & -0.54 & 0.47 & 0.30 & $-1.59^{c}$ \\
\hline Median & $1.22^{\mathrm{a}}$ & $1.24^{\mathrm{a}}$ & $1.36^{\mathrm{a}}$ & $0.51^{\mathrm{a}}$ & $1.16^{\mathrm{a}}$ & $1.17^{\mathrm{a}}$ & $0.81^{\mathrm{a}}$ & $0.62^{\mathrm{a}}$ & 0.91 & $1.48^{\mathrm{a}}$ & 0.56 & $-0.44^{\mathrm{c}}$ & $-0.75^{b}$ & 0.41 & 0.31 & -0.61 \\
\hline $\mathrm{N}$ & 27,665 & 26,123 & 17,119 & 4,060 & 4,663 & 281 & 1,542 & 686 & 193 & 304 & 359 & & & & & \\
\hline \multicolumn{17}{|c|}{ Cross-border deals (CBA) } \\
\hline Mean & $1.95^{\mathrm{a}}$ & $1.78^{\mathrm{a}}$ & $0.96^{\mathrm{a}}$ & $2.37^{\mathrm{a}}$ & $3.14^{\mathrm{a}}$ & 4.41 & $3.46^{\mathrm{a}}$ & $1.70^{\mathrm{b}}$ & $14.45^{\mathrm{a}}$ & $6.51^{\mathrm{a}}$ & 1.37 & $1.69^{\mathrm{b}}$ & 0.74 & $12.07^{\mathrm{a}}$ & $3.37^{\mathrm{c}}$ & -3.04 \\
\hline Median & $0.78^{\mathrm{a}}$ & $0.72^{\mathrm{a}}$ & $0.62^{\mathrm{a}}$ & -0.23 & $1.67^{\mathrm{a}}$ & 1.58 & $1.21^{\mathrm{a}}$ & 0.58 & $7.88^{\mathrm{a}}$ & 2.91 & 1.37 & $0.49^{\mathrm{c}}$ & -0.04 & $8.11^{\mathrm{a}}$ & 1.25 & -0.21 \\
\hline $\mathrm{N}$ & 2,888 & 2,588 & 1,483 & 448 & 620 & 37 & 300 & 156 & 26 & 46 & 72 & & & & & \\
\hline \multicolumn{17}{|c|}{ Domestic vs. Cross-border deals } \\
\hline Mean & $0.49^{\mathrm{b}}$ & $0.68^{\mathrm{a}}$ & $1.36^{\mathrm{a}}$ & 0.31 & -0.44 & -1.08 & $-1.28^{c}$ & 0.09 & $-11.30^{\mathrm{a}}$ & $-3.52^{c}$ & 0.37 & & & & & \\
\hline Median & $0.44^{\mathrm{a}}$ & $0.52^{\mathrm{a}}$ & $0.74^{\mathrm{a}}$ & $0.73^{c}$ & -0.50 & -0.41 & -0.40 & 0.04 & $-6.97^{a}$ & -1.44 & -0.81 & & & & & \\
\hline
\end{tabular}

Panel B: The form of second part (deferred) payment in earnout deals and acquirers' announcement period gains.

\begin{tabular}{ccc}
\hline Initial payment & Deferred payment & Acquirers' returns (CAR) in \% \\
\hline Cash & Cash & $1.74^{\mathrm{a}}$ \\
Cash & Stock & $8.22^{\mathrm{a}}$ \\
Stock & Cash & 7.58 \\
Stock & Stock & $14.45^{\mathrm{b}}$ \\
\hline
\end{tabular}


Table 4: The determinants of acquirers' gains: Multivariate analysis

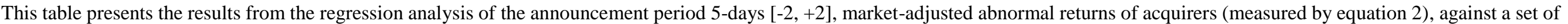

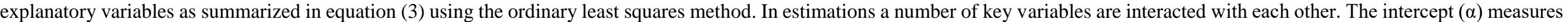

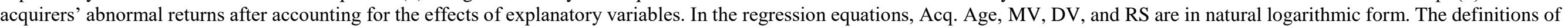

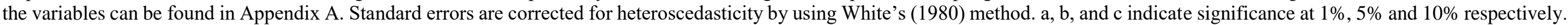

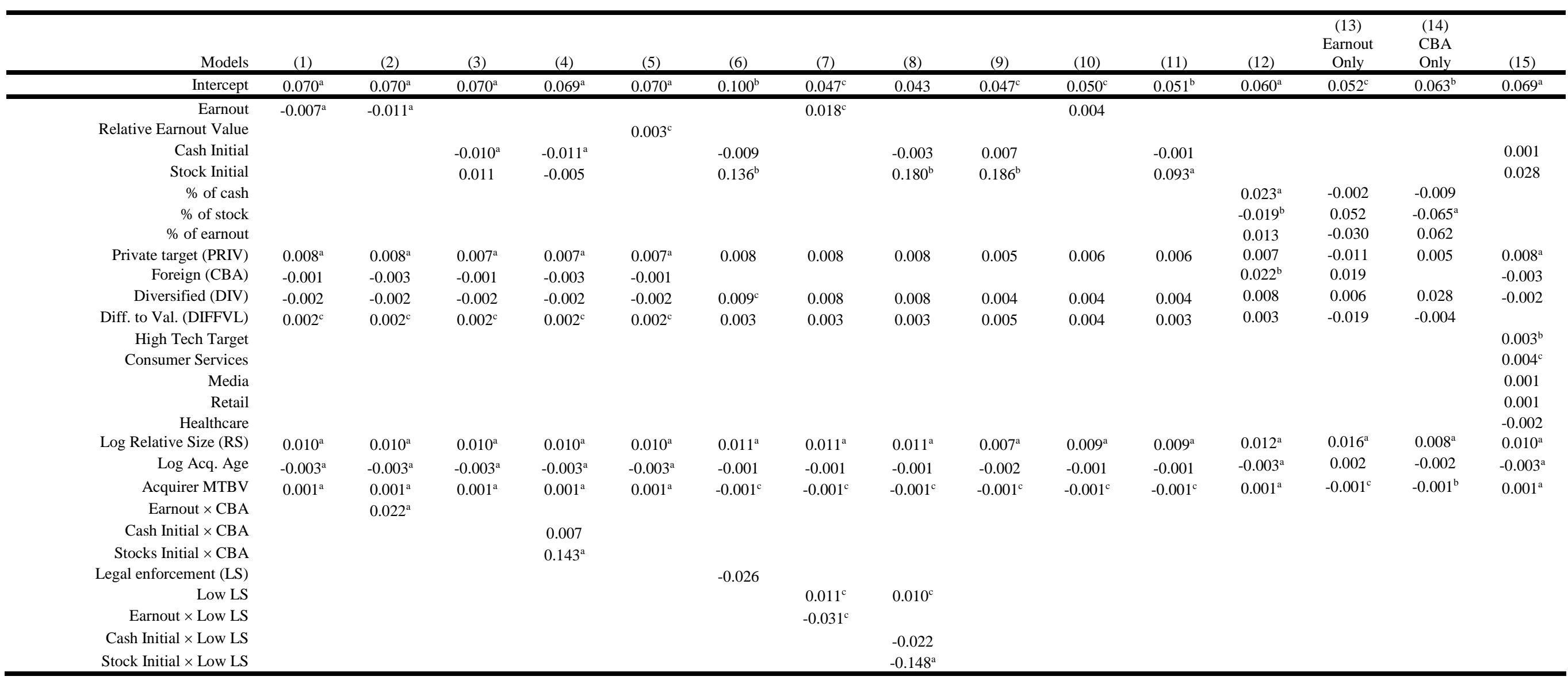

Continued 


\begin{tabular}{|c|c|c|c|c|c|c|c|c|c|c|c|c|c|c|c|}
\hline Models & (1) & (2) & (3) & (4) & (5) & (6) & (7) & (8) & (9) & $(10)$ & (11) & (12) & $\begin{array}{c}(13) \\
\text { Earnout } \\
\text { Only }\end{array}$ & $\begin{array}{l}(14) \\
\text { CBA } \\
\text { Only } \\
\end{array}$ & $(15)$ \\
\hline Pol. Stability (PS) & & & & & & & & & $0.009^{\mathrm{a}}$ & & & & & $0.009^{\mathrm{a}}$ & \\
\hline High PS & & & & & & & & & & 0.002 & 0.004 & & & & \\
\hline Earnout $\times$ High PS & & & & & & & & & & $0.045^{\mathrm{a}}$ & & & & & \\
\hline Cash Initial $\times$ High PS & & & & & & & & & & & -0.002 & & & & \\
\hline Stock Initial $\times$ High PS & & & & & & & & & & & $0.144^{\mathrm{b}}$ & & & & \\
\hline Foreign $\times \%$ of cash & & & & & & & & & & & & $-0.022^{\mathrm{c}}$ & -0.007 & & \\
\hline Foreign $\times \%$ of stock & & & & & & & & & & & & $-0.021^{\mathrm{c}}$ & $0.098^{\mathrm{b}}$ & & \\
\hline Foreign $\times \%$ of earnout & & & & & & & & & & & & -0.002 & -0.027 & & \\
\hline Diversified $\times \%$ of cash & & & & & & & & & & & & -0.010 & -0.013 & -0.028 & \\
\hline Diversified $\times \%$ of stock & & & & & & & & & & & & 0.004 & $-0.074^{\mathrm{b}}$ & -0.016 & \\
\hline Diversified $\times \%$ of earnout & & & & & & & & & & & & -0.015 & 0.010 & -0.016 & \\
\hline Difficult to value $\times \%$ of cash & & & & & & & & & & & & 0.002 & 0.025 & 0.005 & \\
\hline Difficult to value $\times \%$ of stock & & & & & & & & & & & & -0.005 & 0.027 & 0.037 & \\
\hline Difficult to value $\times \%$ of earnout & & & & & & & & & & & & -0.007 & 0.015 & 0.034 & \\
\hline Private Target $\times \%$ of cash & & & & & & & & & & & & $-0.010^{\mathrm{c}}$ & 0.007 & -0.004 & \\
\hline Private Target $\times \%$ of stock & & & & & & & & & & & & $0.045^{\mathrm{a}}$ & -0.022 & $0.043^{c}$ & \\
\hline Private Target $\times \%$ of earnout & & & & & & & & & & & & -0.014 & 0.023 & $-0.102^{\mathrm{c}}$ & \\
\hline Foreign $\times$ Cash Initial & & & & & & & & & & & & & & & 0.007 \\
\hline Foreign $\times$ Stock Initial & & & & & & & & & & & & & & & $0.136^{\mathrm{a}}$ \\
\hline Diversified $\times$ Cash Initial & & & & & & & & & & & & & & & -0.003 \\
\hline Diversified $\times$ Stock Initial & & & & & & & & & & & & & & & $-0.056^{\mathrm{a}}$ \\
\hline High Tech $\times$ Cash Initial & & & & & & & & & & & & & & & -0.001 \\
\hline High Tech $\times$ Stock Initial & & & & & & & & & & & & & & & -0.024 \\
\hline Cons Services $\times$ Cash Initial & & & & & & & & & & & & & & & -0.017 \\
\hline Cons Services $\times$ Stock Initial & & & & & & & & & & & & & & & -0.013 \\
\hline Media $\times$ Cash Initial & & & & & & & & & & & & & & & -0.016 \\
\hline Media $\times$ Stock Initial & & & & & & & & & & & & & & & $0.060^{\mathrm{c}}$ \\
\hline Retail $\times$ Cash Initial & & & & & & & & & & & & & & & 0.010 \\
\hline Retail $\times$ Stock Initial & & & & & & & & & & & & & & & 0.029 \\
\hline Healthcare $\times$ Cash Initial & & & & & & & & & & & & & & & 0.008 \\
\hline Healthcare $\times$ Stock Initial & & & & & & & & & & & & & & & $-0.053^{\mathrm{c}}$ \\
\hline Private Target $\times$ Cash Initial & & & & & & & & & & & & & & & $-0.015^{\mathrm{b}}$ \\
\hline Private Target $\times$ Stock Initial & & & & & & & & & & & & & & & 0.008 \\
\hline$F$-Stat & $90.00^{\mathrm{a}}$ & $80.96^{\mathrm{a}}$ & $80.11^{\mathrm{a}}$ & $68.38^{\mathrm{a}}$ & $89.48^{\mathrm{a}}$ & $14.56^{\mathrm{a}}$ & $12.33^{\mathrm{a}}$ & $12.37^{\mathrm{a}}$ & $14.75^{\mathrm{a}}$ & $13.40^{\mathrm{a}}$ & $13.25^{\mathrm{a}}$ & $48.71^{\mathrm{a}}$ & $5.86^{\mathrm{a}}$ & $6.64^{\mathrm{a}}$ & $26.95^{\mathrm{a}}$ \\
\hline$R$-squared & 2.55 & 2.58 & 2.55 & 2.66 & 2.53 & 7.43 & 6.37 & 7.70 & 7.76 & 6.38 & 7.62 & 3.75 & 7.43 & 7.44 & 2.76 \\
\hline$N$ & 27,548 & 27,548 & 27,548 & 27,548 & 27,548 & 1,642 & 1,642 & 1,642 & 1,589 & 1,589 & 1,589 & 27,548 & 1,631 & 1,589 & 27,548 \\
\hline
\end{tabular}


Table 5: Acquirers' gains: Univariate analysis (selection bias addressed)

This table presents the announcement period, 5-day $[-2,+2]$, abnormal returns (in \%) of treated (earnout and sub-groupings according to the initial payment in earnout deals) and control (non-earnout and sub-groups in cash, stocks combo and other) deals, for all deals, as well as by domiciles of targets. Differences in the gains of the treated (earnout) and the control (non-earnout) groups, for each category of sub-samples, are also presented. The control group is identified using the PSM method based on 1:1 matching ratio and 0.01 caliper (a caliper is the maximum tolerated difference between matched subjects - treated and control objects). $N$ refers to the number of observations in each deal portfolio. Appendix A provides the definitions of the variables. a, b, and c indicate significance at 1\%, 5\% and $10 \%$ respectively.

\begin{tabular}{|c|c|c|c|c|c|c|c|c|c|c|c|c|c|c|c|}
\hline & \multicolumn{5}{|c|}{ Treated (Earnout deals) } & \multicolumn{5}{|c|}{ Control (Non-earnout deals) } & \multicolumn{5}{|c|}{ Treated vs. Control } \\
\hline & Earnout & $\begin{array}{l}\text { Cash } \\
\text { Initial }\end{array}$ & $\begin{array}{l}\text { Stock } \\
\text { Initial }\end{array}$ & $\begin{array}{c}\text { Combo } \\
\text { Initial }\end{array}$ & $\begin{array}{l}\text { Other } \\
\text { Initial }\end{array}$ & $\begin{array}{l}\text { Non } \\
\text { Earnout }\end{array}$ & Cash & Stocks & Combo & Other & $\begin{array}{c}\text { Earnout } \\
\text { vs. } \\
\text { Non } \\
\text { Earnout }\end{array}$ & $\begin{array}{c}\text { Cash } \\
\text { Initial } \\
\text { vs. } \\
\text { Cash }\end{array}$ & $\begin{array}{c}\text { Stock } \\
\text { Initial } \\
\text { vs. } \\
\text { Stocks }\end{array}$ & $\begin{array}{c}\text { Combo } \\
\text { Initial } \\
\text { vs. } \\
\text { Combo }\end{array}$ & $\begin{array}{c}\text { Other } \\
\text { Initial } \\
\text { vs. } \\
\text { Other }\end{array}$ \\
\hline \multicolumn{16}{|c|}{ All deals } \\
\hline Mean & $2.39^{\mathrm{a}}$ & $1.77^{\mathrm{a}}$ & $4.49^{\mathrm{a}}$ & $3.46^{\mathrm{a}}$ & $1.68^{\mathrm{a}}$ & $3.42^{\mathrm{a}}$ & $2.48^{a}$ & $7.59^{\mathrm{a}}$ & $2.88^{\mathrm{a}}$ & $4.19^{\mathrm{a}}$ & $-1.03^{b}$ & $-0.71^{\mathrm{c}}$ & $-3.10^{c}$ & 0.58 & $-2.51^{2}$ \\
\hline Median & $0.89^{\mathrm{a}}$ & $0.62^{\mathrm{a}}$ & $1.74^{\mathrm{b}}$ & $1.67^{\mathrm{a}}$ & $0.74^{\mathrm{c}}$ & $1.31^{\mathrm{a}}$ & $1.21^{\mathrm{a}}$ & $1.59^{\mathrm{b}}$ & $0.67^{\mathrm{c}}$ & $1.56^{\mathrm{a}}$ & $-0.42^{b}$ & $-0.59^{b}$ & 0.15 & $1.00^{\mathrm{c}}$ & $-0.82^{\mathrm{b}}-\mathrm{c} \cdot \mathrm{c}$ \\
\hline $\mathrm{N}$ & 1,842 & 842 & 219 & 350 & 431 & 1,842 & 840 & 209 & 345 & 230 & & & & & \\
\hline \multicolumn{16}{|c|}{ Domestic deals (DOM) } \\
\hline Mean & $2.19^{\mathrm{a}}$ & $1.79^{\mathrm{a}}$ & $3.15^{\mathrm{a}}$ & $3.00^{\mathrm{a}}$ & $1.75^{\mathrm{a}}$ & $3.33^{\mathrm{a}}$ & $3.16^{\mathrm{a}}$ & $6.26^{\mathrm{a}}$ & $2.87^{\mathrm{a}}$ & $3.65^{\mathrm{a}}$ & $-1.14^{\mathrm{b}}$ & $-1.37^{\mathrm{a}}$ & $-3.11^{\mathrm{c}}$ & 0.13 & $-1.90^{\circ}$ \\
\hline Median & $0.81^{\mathrm{a}}$ & $0.62^{\mathrm{a}}$ & 0.91 & $1.48^{\mathrm{a}}$ & 0.56 & 1.05 & $1.64^{\mathrm{a}}$ & 3.38 & $0.73^{c}$ & $1.55^{\mathrm{a}}$ & -0.24 & $-1.02^{\mathrm{a}}$ & $-2.47^{b}$ & 0.75 & 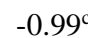 \\
\hline $\mathrm{N}$ & 1,542 & 686 & 193 & 304 & 359 & 1,525 & 685 & 193 & 294 & 197 & & & & & \\
\hline \multicolumn{16}{|c|}{ Cross-border deals (CBA) } \\
\hline Mean & $3.46^{\mathrm{a}}$ & $1.69^{\mathrm{b}}$ & $14.45^{\mathrm{a}}$ & $6.51^{\mathrm{a}}$ & 1.37 & $1.26^{\mathrm{c}}$ & -0.59 & -0.60 & 1.89 & 6.19 & $2.20^{\mathrm{b}}$ & $2.27^{\mathrm{b}}$ & $15.05^{\mathrm{a}}$ & $4.62^{\mathrm{c}}$ & -4.82 \\
\hline Median & $1.21^{\mathrm{a}}$ & 0.37 & $7.88^{\mathrm{a}}$ & 2.91 & 1.37 & 0.57 & -0.27 & -1.53 & 0.98 & -0.29 & $0.64^{\mathrm{c}}$ & $0.64^{\mathrm{c}}$ & $9.41^{\mathrm{a}}$ & 1.93 & 1.66 \\
\hline $\mathrm{N}$ & 300 & 115 & 26 & 46 & 72 & 293 & 113 & 14 & 33 & 20 & & & & & \\
\hline
\end{tabular}


Table 6: The determinants of acquirers' gains: Multivariate analysis (selection bias addressed)

This table presents the results from the regression analysis of the announcement period 5-days [-2, +2], market-adjusted abnormal returns of the matched sample of acquirers, against a set of explanatory variables as well as interaction-terms between some of the key variables. The models (various forms of equation 3 ) are estimated using the ordinary least squares method. The matched sample includes treated deals and control deals. The PSM method is used to construct the matched sample based on 5:1 matching ratio and 0.01 caliper (for each treated deal the PSM matches 5 control deals). A caliper is the maximum tolerated difference between matched subjects (treated and control objects). The intercept $(\alpha)$ measures acquirers' abnormal returns after accounting for the effects of explanatory variables. In the regression equation Age, MV, DV, and RS are in natura logarithmic form. The definition of the variables can be found in Appendix A. Standard errors are corrected for heteroscedasticity by using White's (1980) method. a, b, and c indicate significance at $1 \%, 5 \%$ and $10 \%$ respectively.

\begin{tabular}{|c|c|c|c|c|c|c|c|c|c|c|c|c|c|c|c|}
\hline Models & $(1)$ & $(2)$ & (3) & (4) & $(5)$ & $(6)$ & (7) & $(8)$ & $(9)$ & $(10)$ & (11) & $(12)$ & $\begin{array}{c}(13) \\
\text { Earnout } \\
\text { Only }\end{array}$ & $\begin{array}{l}(14) \\
\text { CBA } \\
\text { Only }\end{array}$ & $(15)$ \\
\hline Intercept & $0.068^{\mathrm{a}}$ & $0.069^{\mathrm{a}}$ & $0.066^{\mathrm{a}}$ & $0.066^{\mathrm{a}}$ & $0.068^{\mathrm{a}}$ & 0.082 & 0.040 & 0.032 & $0.051^{\mathrm{c}}$ & $0.075^{\mathrm{b}}$ & $0.073^{\mathrm{b}}$ & $0.051^{\mathrm{a}}$ & $0.054^{\mathrm{c}}$ & $0.094^{\mathrm{c}}$ & $0.065^{\mathrm{a}}$ \\
\hline $\begin{array}{r}\text { Earnout } \\
\text { Relative Earnout Value }\end{array}$ & $-0.010^{\mathrm{a}}$ & $-0.014^{\mathrm{a}}$ & & & $0.004^{\mathrm{b}}$ & & $0.021^{\mathrm{b}}$ & & & 0.003 & & & & & \\
\hline Cash Initial & & & $-0.010^{\mathrm{a}}$ & $-0.012^{\mathrm{a}}$ & & -0.005 & & 0.003 & 0.009 & & 0.004 & & & & 0.001 \\
\hline Stock Initial & & & 0.008 & -0.009 & & $0.142^{\mathrm{b}}$ & & $0.187^{\mathrm{b}}$ & $0.203^{\mathrm{a}}$ & & $0.128^{\mathrm{a}}$ & & & & 0.023 \\
\hline$\%$ of cash & & & & & & & & & & & & $0.027^{\mathrm{b}}$ & 0.001 & -0.042 & \\
\hline$\%$ of stock & & & & & & & & & & & & -0.021 & 0.049 & $-0.097^{b}$ & \\
\hline$\%$ of earnout & & & & & & & & & & & & 0.013 & -0.029 & 0.026 & \\
\hline Private target (PRIV) & $0.008^{\mathrm{a}}$ & $0.008^{\mathrm{a}}$ & $0.008^{\mathrm{a}}$ & $0.007^{\mathrm{a}}$ & $0.008^{\mathrm{a}}$ & -0.001 & 0.001 & -0.001 & 0.004 & 0.002 & -0.001 & 0.008 & -0.011 & 0.003 & $0.008^{\mathrm{a}}$ \\
\hline Foreign (CBA) & -0.002 & $-0.008^{b}$ & -0.002 & $-0.006^{c}$ & -0.002 & & & & & & & 0.013 & 0.019 & & $-0.006^{b}$ \\
\hline Diversified (DIV) & 0.001 & 0.002 & 0.001 & 0.002 & 0.001 & -0.002 & -0.005 & -0.004 & -0.006 & -0.006 & -0.007 & 0.011 & 0.006 & 0.038 & 0.002 \\
\hline Diff. to Val. (DIFFVL) & $0.005^{\mathrm{c}}$ & $0.005^{\mathrm{c}}$ & $0.005^{\mathrm{c}}$ & $0.004^{c}$ & $0.005^{\mathrm{c}}$ & 0.002 & 0.004 & 0.001 & -0.002 & 0.001 & -0.002 & 0.004 & -0.019 & -0.048 & \\
\hline High Tech Target & & & & & & & & & & & & & & & $0.006^{\mathrm{c}}$ \\
\hline Consumer Services & & & & & & & & & & & & & & & 0.010 \\
\hline Media & & & & & & & & & & & & & & & 0.008 \\
\hline Retail & & & & & & & & & & & & & & & -0.002 \\
\hline Healthcare & & & & & & & & & & & & & & & -0.006 \\
\hline Acquirer MTBV & -0.001 & -0.001 & -0.001 & -0.001 & -0.001 & 0.001 & 0.001 & 0.001 & 0.001 & -0.001 & -0.001 & 0.001 & $-0.001^{\mathrm{c}}$ & -0.001 & -0.001 \\
\hline Earnout $\times$ CBA & & $0.027^{\mathrm{a}}$ & & & & & & & & & & & & & \\
\hline Cash Initial $\times$ CBA & & & & 0.012 & & & & & & & & & & & \\
\hline Stocks Initial $\times$ CBA & & & & $0.161^{\mathrm{a}}$ & & & & & & & & & & & \\
\hline Legal enforcement (LS) & & & & & & -0.023 & & & & & & & & & \\
\hline Low LS & & & & & & & 0.009 & 0.006 & & & & & & & \\
\hline Earnout $\times$ Low LS & & & & & & & $-0.033^{c}$ & & & & & & & & \\
\hline Cash Initial $\times$ Low LS & & & & & & & & -0.026 & & & & & & & \\
\hline Stock Initial $\times$ Low LS & & & & & & & & $-0.148^{\mathrm{b}}$ & & & & & & & \\
\hline
\end{tabular}




\begin{tabular}{|c|c|c|c|c|c|c|c|c|c|c|c|c|c|c|c|}
\hline Models & (1) & (2) & (3) & (4) & (5) & (6) & (7) & (8) & (9) & $(10)$ & (11) & (12) & $\begin{array}{l}(13) \\
\text { Earnout } \\
\text { Only }\end{array}$ & $\begin{array}{l}(14) \\
\text { CBA } \\
\text { Only }\end{array}$ & (15) \\
\hline Pol. Stability (PS) & & & & & & & & & $0.010^{c}$ & & & & & $0.010^{c}$ & \\
\hline High PS & & & & & & & & & & -0.003 & 0.004 & & & & \\
\hline Earnout $\times$ High PS & & & & & & & & & & $0.048^{\mathrm{a}}$ & & & & & \\
\hline Cash Initial $\times$ High PS & & & & & & & & & & & -0.006 & & & & \\
\hline Stock Initial $\times$ High PS & & & & & & & & & & & $0.117^{\mathrm{c}}$ & & & & \\
\hline Foreign $\times \%$ of cash & & & & & & & & & & & & -0.014 & -0.011 & & \\
\hline Foreign $\times \%$ of stock & & & & & & & & & & & & -0.022 & $0.105^{\mathrm{b}}$ & & \\
\hline Diversified $\times \%$ of cash & & & & & & & & & & & & -0.013 & -0.016 & -0.038 & \\
\hline Diversified $\times \%$ of stock & & & & & & & & & & & & -0.001 & $-0.071^{\mathrm{b}}$ & $-0.085^{\mathrm{b}}$ & \\
\hline Diversified $\times \%$ of earnout & & & & & & & & & & & & -0.019 & 0.009 & -0.040 & \\
\hline Difficult to value $\times \%$ of cash & & & & & & & & & & & & 0.004 & 0.024 & 0.046 & \\
\hline Difficult to value $\times \%$ of stock & & & & & & & & & & & & -0.001 & 0.028 & $0.078^{\mathrm{c}}$ & \\
\hline Jifficult to value $\times \%$ of earnout & & & & & & & & & & & & -0.009 & 0.014 & $0.084^{\mathrm{c}}$ & \\
\hline Private $\times \%$ of cash & & & & & & & & & & & & -0.013 & 0.006 & 0.001 & \\
\hline Private $\times \%$ of stock & & & & & & & & & & & & $0.049^{\mathrm{a}}$ & -0.021 & $0.066^{\mathrm{c}}$ & \\
\hline Private $\times \%$ of earnout & & & & & & & & & & & & -0.015 & 0.023 & $-0.105^{\mathrm{c}}$ & \\
\hline Foreign $\times$ Stock Initial & & & & & & & & & & & & & & & $0.156^{\mathrm{a}}$ \\
\hline Diversified $\times$ Cash Initial & & & & & & & & & & & & & & & -0.006 \\
\hline Diversified $\times$ Stock Initial & & & & & & & & & & & & & & & $-0.057^{\mathrm{a}}$ \\
\hline High Tech $\times$ Cash Initial & & & & & & & & & & & & & & & -0.003 \\
\hline High Tech $\times$ Stock Initial & & & & & & & & & & & & & & & -0.026 \\
\hline Consumer Serv $\times$ Cash Initial & & & & & & & & & & & & & & & $-0.025^{c}$ \\
\hline Consumer Serv $\times$ Stock Initial & & & & & & & & & & & & & & & -0.026 \\
\hline Media $\times$ Cash Initial & & & & & & & & & & & & & & & -0.023 \\
\hline Media $\times$ Stock Initial & & & & & & & & & & & & & & & $0.079^{c}$ \\
\hline Retail $\times$ Cash Initial & & & & & & & & & & & & & & & 0.014 \\
\hline Retail $\times$ Stock Initial & & & & & & & & & & & & & & & 0.034 \\
\hline Healthcare $\times$ Cash Initial & & & & & & & & & & & & & & & 0.014 \\
\hline Healthcare $\times$ Stock Initial & & & & & & & & & & & & & & & $-0.052^{\mathrm{c}}$ \\
\hline Private Target $\times$ Cash Initial & & & & & & & & & & & & & & & $-0.016^{\mathrm{b}}$ \\
\hline Private Target $\times$ Stock Initial & & & & & & & & & & & & & & & 0.010 \\
\hline$F$-Stat & $37.14^{\mathrm{a}}$ & $33.95^{\mathrm{a}}$ & $32.70^{\mathrm{a}}$ & $29.41^{\mathrm{a}}$ & $36.53^{\mathrm{a}}$ & $5.61^{\mathrm{a}}$ & $2.94^{\mathrm{a}}$ & $5.21^{\mathrm{a}}$ & $7.11^{\mathrm{a}}$ & $4.08^{\mathrm{a}}$ & $6.39^{\mathrm{a}}$ & $17.02^{\mathrm{a}}$ & $5.81^{\mathrm{a}}$ & $2.70^{\mathrm{a}}$ & $12.20^{\mathrm{a}}$ \\
\hline$R$-squared & 3.76 & 3.87 & 3.73 & 4.09 & 3.71 & 6.72 & 3.64 & 7.57 & 8.63 & 4.62 & 8.52 & 4.71 & 7.38 & 7.13 & 4.46 \\
\hline$N$ & 7,603 & 7,603 & 7,603 & 7,603 & 7,603 & 711 & 711 & 711 & 687 & 767 & 767 & 7,603 & 1,628 & 687 & 7,603 \\
\hline
\end{tabular}


Table 7: Initial and deferred payments in earnout finance deal: A multivariate analysis of acquirers' gains

This table presents the results from the regression analysis of the announcement period 5-days [-2, +2], market-adjusted abnormal returns of acquirers, measured by equation (2), against a set of explanatory variables. The models (equation 3 ) are estimated using the ordinary least squares method. The intercept ( $\alpha$ ) measures acquirers' abnormal returns after accounting for the effects of explanatory variables. In the equation Acq. Age, MV, DV, and RS are in natural logarithmic form. The definitions of the variables can be found in Appendix A. Standard errors are corrected for heteroscedasticity by using White's (1980) method. a, b, and c indicate significance at $1 \%, 5 \%$ and $10 \%$ respectively.

\begin{tabular}{|c|c|c|c|c|c|c|c|c|c|c|c|}
\hline Models & (1) & (2) & (3) & (4) & (5) & (6) & (7) & $(8)$ & (9) & $(10)$ & (11) \\
\hline Intercept & -0.036 & -0.041 & $-0.104^{c}$ & -0.076 & -0.052 & -0.083 & -0.052 & $-0.089^{c}$ & $-0.094^{b}$ & -0.055 & -0.055 \\
\hline Relative Earnout Value & $0.004^{\mathrm{c}}$ & $0.003^{c}$ & -0.014 & $0.004^{c}$ & $0.003^{\mathrm{c}}$ & -0.015 & $0.003^{\mathrm{c}}$ & -0.014 & $0.004^{c}$ & $0.004^{c}$ & $0.004^{\mathrm{c}}$ \\
\hline Cash Initial & 0.005 & & & & & & & & 0.003 & & \\
\hline Cash Deferred & -0.006 & & & & & & & & & & \\
\hline Cash (Initial \& Deferred) & & 0.004 & 0.010 & & & & 0.005 & 0.013 & & & \\
\hline Stock Initial & & & & $-0.048^{b}$ & & & & & & & \\
\hline Stock Deferred & & & & $0.066^{\mathrm{a}}$ & & & & & $0.063^{\mathrm{a}}$ & & \\
\hline Stock (Initial \& Deferred) & & & & & $0.033^{\mathrm{c}}$ & $0.060^{\mathrm{a}}$ & $0.035^{\mathrm{c}}$ & $0.063^{\mathrm{a}}$ & & & \\
\hline Cash Initial \& Stock Deferred & & & & & & & & & & $0.075^{\mathrm{a}}$ & $0.077^{\mathrm{a}}$ \\
\hline Private target (PRIV) & $0.020^{\mathrm{b}}$ & $0.020^{\mathrm{b}}$ & $0.025^{\mathrm{b}}$ & $0.021^{\mathrm{b}}$ & $0.019^{\mathrm{b}}$ & $0.021^{\mathrm{b}}$ & $0.020^{\mathrm{b}}$ & $0.021^{\mathrm{b}}$ & $0.022^{\mathrm{b}}$ & $0.023^{\mathrm{a}}$ & $0.023^{\mathrm{a}}$ \\
\hline Foreign (CBA) & $0.019^{c}$ & $0.018^{c}$ & $0.036^{\mathrm{a}}$ & $0.019^{c}$ & $0.019^{c}$ & 0.016 & $0.018^{c}$ & $0.023^{\mathrm{c}}$ & $0.020^{\mathrm{b}}$ & $0.017^{\mathrm{c}}$ & $0.019^{c}$ \\
\hline Diversified (DIV) & 0.006 & 0.007 & 0.008 & 0.002 & 0.007 & 0.014 & 0.008 & $0.014^{\mathrm{c}}$ & 0.003 & 0.003 & 0.003 \\
\hline Diff. to Val. (DIFFVL) & -0.009 & -0.009 & -0.003 & $-0.018^{b}$ & -0.010 & -0.008 & -0.010 & -0.008 & $-0.017^{c}$ & $-0.013^{c}$ & -0.013 \\
\hline Log Relative Size (RS) & $0.010^{\mathrm{a}}$ & $0.009^{\mathrm{a}}$ & $0.013^{\mathrm{b}}$ & $0.007^{\mathrm{b}}$ & $0.009^{\mathrm{a}}$ & $0.008^{\mathrm{b}}$ & $0.009^{b}$ & $0.008^{b}$ & $0.007^{\mathrm{b}}$ & $0.008^{\mathrm{a}}$ & $0.008^{\mathrm{a}}$ \\
\hline Log Acquirer Age (Age) & 0.007 & 0.007 & $0.016^{\mathrm{b}}$ & $0.010^{c}$ & 0.008 & $0.012^{\mathrm{b}}$ & 0.008 & $0.013^{\mathrm{b}}$ & $0.012^{\mathrm{b}}$ & 0.008 & 0.008 \\
\hline Acquirer MTBV & -0.001 & -0.001 & -0.001 & 0.001 & -0.001 & -0.002 & -0.001 & -0.002 & 0.001 & -0.001 & 0.000 \\
\hline$($ Cash Initial \& Deferred $) \times \mathrm{CBA}$ & & & $-0.041^{\mathrm{c}}$ & & & & & & & & \\
\hline$($ Stock Initial \& Deferred $) \times \mathrm{CBA}$ & & & & & & $0.284^{\mathrm{a}}$ & & & & & \\
\hline$($ Cash Initial \& Stock Deferred $) \times$ CBA & & & & & & & & $0.277^{\mathrm{a}}$ & & & -0.014 \\
\hline$F$-Stat & $2.04^{\mathrm{b}}$ & $2.22^{\mathrm{b}}$ & $4.05^{\mathrm{a}}$ & $6.07^{\mathrm{a}}$ & $2.33^{\mathrm{b}}$ & $9.40^{\mathrm{a}}$ & $2.12^{\mathrm{b}}$ & $7.99^{\mathrm{a}}$ & $5.59^{\mathrm{a}}$ & $6.18^{\mathrm{a}}$ & $5.57^{\mathrm{a}}$ \\
\hline$R$-squared & 5.62 & 5.50 & 9.38 & 15.03 & 5.74 & 19.38 & 5.81 & 19.77 & 14.01 & 13.91 & 13.96 \\
\hline$N$ & 354 & 354 & 402 & 354 & 354 & 402 & 354 & 402 & 354 & 354 & 354 \\
\hline
\end{tabular}


Figure 1

Annual distribution of earnout deals relative to all deals

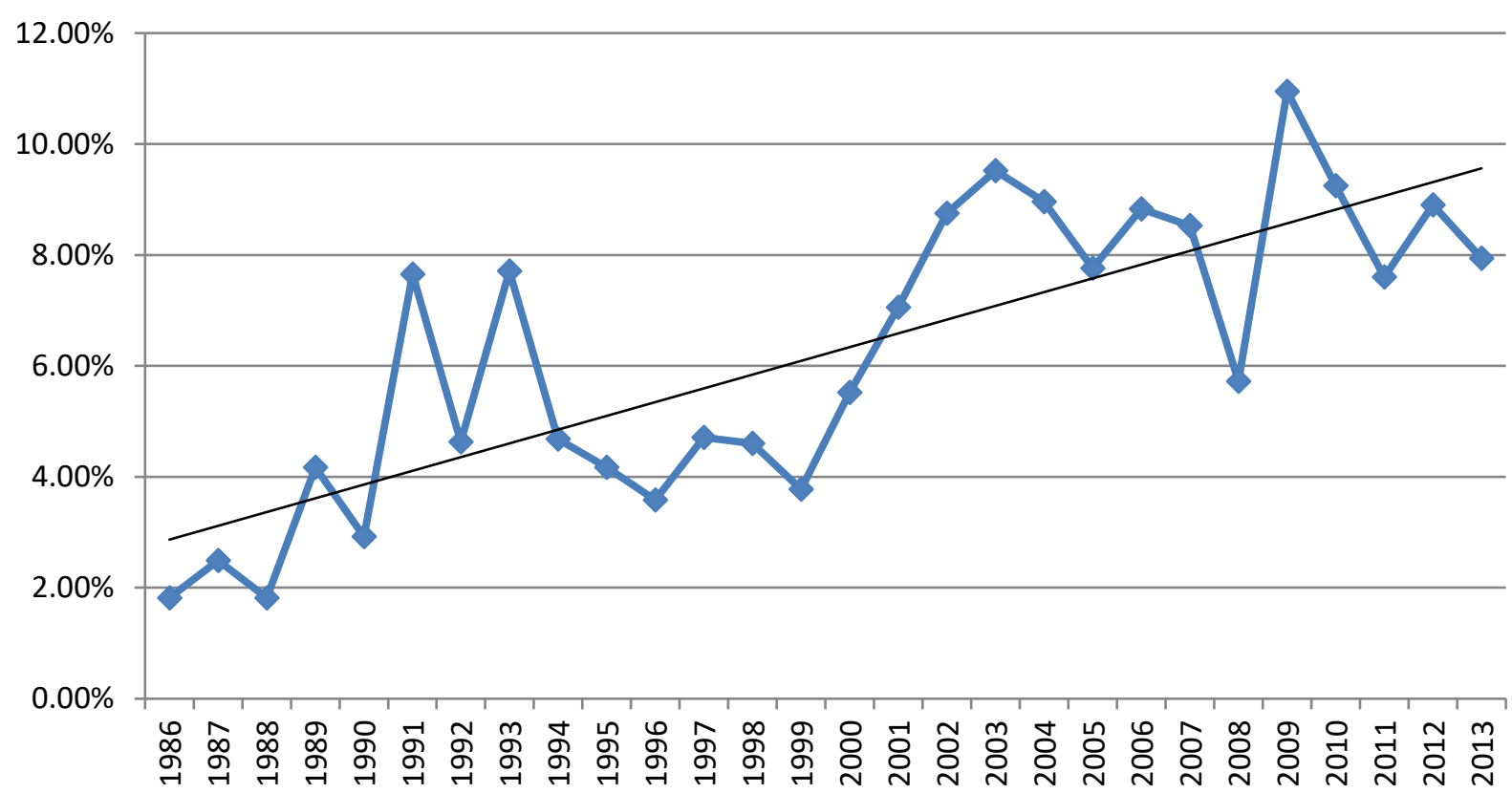

$\_\%$ earnout $\_$Linear (\% earnout) 